\title{
4C: Diagnostic aspects of $H$. pylori infections
}

\section{C:01 SEROLOGY IS BEST USED IF ENDOSCOPY IS OMITTED IN SEROPOSITIVE CASES!}

B.F.M. Werdmuller, A.B.M.M. van der Putten, R.J.L.F. Loffeld. Department of Internal Medicine, Ziekenhuis De Heel, Zaandam, The Netherlands

Screening for IgG antibodies against HP can be used to reduce endoscopy workload by omitting endoscopy in selected cases. The present study was done in order to assess the best screening strategy. From all patients, referred for endoscopy, from 3/1994 till 3/1995 a serum sample was taken. IgG antibodies against HP were detected using a home-made ELISA technique. During the study period 1527 patients underwent upper GI endoscopy. In 233 cases endoscopy was done because of follow-up or serum from the patient was not available. Hence 1293 serum samples were available for analysis. IgG antibodies were present in 622 patients $(48 \%$ ) ( 303 male, 319 female, mean age 57 years, range 17-87), the remainder, 671 (52\%) (316 male, 355 female, mean age 52 years, range 13-84) was negative.

The following abnormalities were seen in the seropositive group: oesophagitis $10 \%$, hiatal hernia $12 \%$, oesophageal cancer $0.5 \%$, Barrett $3.4 \%$, varices $1.9 \%$, candida $1.9 \%$, gastritis $8.5 \%$, GU $3.8 \%$, gastric cancer $1.6 \%$, DU $6.4 \%$, and bulbitis $8.3 \%$. And in the seronegative group: oesophagitis $15 \%$, hiatal hernia $15.4 \%$, oesophageal cancer $0.3 \%$, Barrett $4.3 \%$, varices $1 \%$, candida $1.3 \%$, gastritis $10.6 \%$, GU $1.8 \%$, gastric cancer $0.1 \%$, DU $1.6 \%$, and bulbitis $5.5 \%$. The following abnormalities were seen in the seropositive group below the age of 45 years: oesophagitis $6.8 \%$, hiatal hernia $8 \%$, Barrett $1.3 \%$, varices $1.3 \%$, candida $0.65 \%$, gastritis $6.8 \%$, GU $0.6 \%$, DU $14.5 \%$, and bulbitis $6.8 \%$. And in the seronegative group: oesophagitis $12 \%$, hiatal hernia $6 \%$, Barrett $1.7 \%$, varices $0.4 \%$, gastritis $7.3 \%$, DU $2.6 \%$, and bulbitis $4.7 \%$. If screening would have been applied on the total group of seronegatives than 318 patient would undergo endoscopy and $353(27.3 \%)$ endoscopies could have been saved. Omitting endoscopy in seronegative cases below the age of 45 years would result in $182(14 \%)$ endoscopies saved. If this strategy again is applied on the total group of seropositives than 188 patients still would undergo endoscopy and 434 endoscopies (34\%) would have been saved. Omitting endoscopy in seropositive cases below the age of 45 years would save $119(9 \%)$ endoscopies.

It is concluded that endoscopy can be savely omitted in seropositive cases. Endoscopy in seronegatives will reveal more reflux oesophagitis. In oesophagitis helicobacter infection needs treatment since long term acid suppressive therapy leads to atrophic gastritis. After eradication therapy oesophagits complaints are likely to return and endoscopy will be done. It is of no problem at the present stage of functional dyspepsia to give HP positive dyspeptics eradication therapy. Many patients will benefit from this therapy and the number of recurrent complaints will be low. This study indicates that omitting endoscopy in seropositive cases, regardless of age, reduces the workload more than omitting endoscopy in seronegative cases, $34 \%$ fewer endoscopies versus $27 \%$.

\section{C:02 COST-EFFECTIVE TESTING FOR H. PYLORI AT EGD}

A.F. Cutler ${ }^{1}$, J.L. Goldstein ${ }^{2}$, R. McDaniel ${ }^{3}$, J.J. Chmiel ${ }^{3}$, D.A. Peura ${ }^{4}$. ${ }^{1}$ Sinai Hosp, Detroit, MI, USA; ${ }^{2}$ Univ of Il, Chicago, IL, USA; ${ }^{3}$ Abbott Labs, Il, Chicago, IL, USA; ${ }^{4}$ Univ of VA, Charlottesville, VA, USA

Objective: Determine Hp prevalence at which negative rapid urease tests (RUTs) should be accepted and establish cost-effective secondary test strategies for negative RUTs.

Methods: We modelled Hp testing at initial EGD and assumed RUT would be the test of first choice. We determined cost-effectiveness ratios for the average cost (\$US) per correct diagnosis at various Hp prevalence rates for RUT alone (sens $90 \%$, spec $100 \%$ ) vs. RUT plus secondary test strategies (histology $(93,99)$, serum immunoassay $(93,90)$, whole blood test $(90,87)$, ELISA $(95,95)$ or $\left.\left[{ }^{13} \mathrm{C}\right] \mathrm{UBT}(90,96)\right)$. The base case assumed $75 \% \mathrm{Hp}$ prevalence. It was also assumed that at infection rates of $90 \%$ or greater, no Hp testing would be performed. Results: At Hp prevalence rates less than $67.6 \%$, RUT alone had the lowest average cost per correct dx. At higher infection rates, the combination of RUT and antibody testing (any of 3 ) were more cost-effective than RUT with histology or UBT.

Results were not sensitive to either a $20 \%$ change in antibody test cost or a 5\% variation in accuracy. Conclusions: At low to moderate Hp preva-

\begin{tabular}{lcccccc}
\hline & $\begin{array}{c}\text { RUT } \\
\text { Only }\end{array}$ & $\begin{array}{c}\text { RUT \& } \\
\text { Histo }\end{array}$ & $\begin{array}{c}\text { RUT \& } \\
\text { ELISA }\end{array}$ & $\begin{array}{c}\text { RUT \& } \\
\text { Serum }\end{array}$ & $\begin{array}{c}\text { RUT \& } \\
\text { Wh Bl }\end{array}$ & $\begin{array}{c}\text { RUT \& } \\
\text { UBT }\end{array}$ \\
\hline DX (\%) & 922 & 992 & 984 & 97.0 & 960 & 982 \\
Cost/DX & 226 & 292 & 241 & 226 & 221 & 279 \\
\hline
\end{tabular}

lence (<67.6\%), such as in NUD, RUTs alone are appropriate. Between $67.6 \%-90 \%$, such as GU or complicated DU, negative RUTs should be followed by secondary antibody testing. At highest $\mathrm{Hp}$ prevalence (> $90 \%$ ), uncomplicated DU with no NSAIDs, no Hp tests may be required.

\section{C:03 DETECTION OF CYTOTOXIN ASSOCIATED GENE A (CagA) AS SERODIAGNOSTIC MARKER IN DIAGNOSIS AND TREATMENT OF DUODENAL ULCER (DU) AND NON-ULCER DYSPEPSIA (NUD)}

E. Karczewska, A. Bobrzynski, S.J. Konturek, H. Keanthous. Inst Physiol Univ Sch Med, Krakow, Poland; OraVax Inc, Cambridge, MA, USA

It has been proposed that about $60 \%$ of Helicobacter pylori $(\mathrm{Hp})$ isolates express CagA and that this protein induces serum IgG antibodies (Ab). Infection with $\mathrm{Hp}$ expressing $\mathrm{CagA}$ was suggested to increase the risk of DU but no comparative studies have been made regarding the expression of CagA in DU and NUD during anti-Hp therapy. This study included 50 Hp-positive (by ${ }^{14} \mathrm{C}$-UBT, CLO, histology and culture of gastric biopsy) DU patients with active ulcers, 50 symptomatic NUD patients and 25 Hp-negative healthy control. Serum samples were obtained at day of initial endoscopy, $2 \mathrm{wk}$ after triple therapy (omeprazole $20 \mathrm{mg}$ bd, amoxicillin $750 \mathrm{mg}$ bd and metronidazole $500 \mathrm{mg}$ bd) and $4 \mathrm{wk}$ after completion of this therapy. The presence of serum IgG $\mathrm{Ab}$ to $\mathrm{Hp}$ was determined by ELISA using EIAGEN HP IgG test. Ab to CagA sera were detected by ELISA using recombinant CagA (ORV220) as antigen. All tested Hp-positive DU and NUD patients but none of healthy controls had positive serology for IgG. Serum IgG ab to CagA were positive in $80 \%$ of DU, in $40 \%$ of NUD but in none of healthy controls. After 2 and 6 wk of therapy, which succeeded in 95\% eradication of Hp both in DU and NUD and complete ulcer healing in DU, there was significantly gradual decrease in IgG and CagA titre both in DU and NUD, reaching $\approx 80 \%$ of patients. We conclude that: 1. Expression of CagA is strongly associated with Hp infection and is about twice higher in DU than in NUD patients suggesting that CagA expression increases the risk of DU and may serve as serodiagnostic marker to implement anti-Hp therapy, 2. the decrease in serum IgG and CagA titre may be useful in documentation of the progress in DU healing.

\section{C:04 COST-EFFECTIVE HP DIAGNOSIS AFTER THERAPY}

A.F. Cutler ${ }^{1}$, J.L. Goldstein ${ }^{2}$, R. McDaniel ${ }^{3}$, J.J. Chmiel ${ }^{3}$, D.A. Peura ${ }^{4}$. ${ }^{1}$ Sinai Hosp, Detroit, MI, USA; ${ }^{2}$ Univ of Il, Chicago, IL, USA; ${ }^{3}$ Abbott Labs, Il, Chicago, IL, USA ${ }^{4}$ Univ of VA, Charlottesville, VA, USA

Objective: Most confirm H. pylori (Hp) cure in complicated or refractory ulcers or with recurrent symptoms. Our aim was to determine cost-effective strategies for Hp testing following tx. Methods: We determined costeffectiveness ratios for the average cost (\$US) per correct diagnosis at typical post-tx Hp prevalence rates of $10 \%$ and $30 \% \cdot\left[{ }^{13} \mathrm{C}\right]$ urea breath test (UBT) alone (sens 90, spec 96) was compared with rapid urease test (RUT) alone $(90,100)$ as well as with RUT plus secondary test strategies (histology $(93,99)$, or UBT $(90,96)$ ).

Results: UBT only and RUT only had similar average cost per correct $\mathrm{dx}$ at $10 \%$ and $30 \%$ post-tx Hp prevalence. Costs for secondary testing was higher. Results were not sensitive to a $5 \%$ to $20 \%$ reduction in post-tx RUT sensitivity though the number of total correct $\mathrm{dx}$ did decrease slightly.

Conclusions: The choice of test post-tx is dependent on the need for repeat EGD. If EGD is planned, RUT alone will be the best test strategy. If

\begin{tabular}{|c|c|c|c|c|}
\hline & $\begin{array}{l}\text { UBT } \\
\text { Only }\end{array}$ & $\begin{array}{l}\text { RUT } \\
\text { Only }\end{array}$ & $\begin{array}{l}\text { RUT \& } \\
\text { Histo }\end{array}$ & $\begin{array}{l}\text { RUT \& } \\
\text { UBT }\end{array}$ \\
\hline $\begin{array}{l}\text { Hp prevalence }=10 \% \\
\text { DX (\%) } \\
\text { Cost } / \mathrm{DX}\end{array}$ & $\begin{array}{c}95.2 \\
210\end{array}$ & $\begin{array}{c}99.0 \\
210\end{array}$ & $\begin{array}{l}99.0 \\
440\end{array}$ & $\begin{array}{c}96.1 \\
406\end{array}$ \\
\hline $\begin{array}{l}\text { Hp prevalence }=30 \% \\
\text { DX }(\%) \\
\text { Cost } / D X\end{array}$ & $\begin{array}{l}94.1 \\
212\end{array}$ & $\begin{array}{l}96.9 \\
215\end{array}$ & $\begin{array}{c}99.1 \\
394\end{array}$ & $\begin{array}{c}96.8 \\
366\end{array}$ \\
\hline
\end{tabular}


no EGD is planned, UBT alone is appropriate. Only when gastric tissue is obtained for other reasons can secondary histology be justified for $\mathrm{Hp} \mathrm{dx}$.

\section{C:05 ${ }^{14} \mathrm{C}$-UREA BREATH TEST IN DETECTION OF HELICOBACTER PYLORI-ASSOCIATED GASTRIC DISEASES}

W. Bielanski, J. Pytko, S.J. Konturek, E. Sito. Inst. Physiol. Univ. Sch. Med, Krakow, Poland

High urease activity of Helicobacter pylori $(\mathrm{Hp})$ is used to detect this bacterium by non-invasive urea breath test (UBT). We employed the microdose version of the test in which $37 \mathrm{kBq}$ of ${ }^{14} \mathrm{C}$ urea is given orally in capsule. The objectives of the study were: 1 . to evaluate a microdose (37 $\mathrm{kBq}){ }^{14} \mathrm{C}$-urea enclosed in a quick dissolve capsule; 2 . to assess whether the fasting period is required before the procedure of ${ }^{14} \mathrm{C}$-UBT; 3 . to determine whether breath test results are changed when they are mailed to a remote site for analysis; 4 . to define the diagnostic ranges of ${ }^{14} \mathrm{C}$-UBT. We breath tested 239 consenting patients (18-75 yr old) without previous antibiotic or antiulcer therapy or gastric surgery. The breath samples were analyzed before and at $10 \mathrm{~min}$ intervals after the ingestion of $37 \mathrm{kBq}$ ${ }^{14} \mathrm{C}$-urea by patients prior to their endoscopy. With the cut-off value $>100$ DPM as positive, UBT results correlated highly significant with combined results of invasive gold standards i.e. CLO-test + histology score. The breath test performed locally were almost identical with those read at remote laboratory. The data for fasting and fed states of subjects agreed in $87 \%$. When ${ }^{14} \mathrm{C}$-urea was dissolved in water and confined for $5 \mathrm{~min}$ in the mouth (without swallowing), both $30 \mathrm{Hp}$ positive and $30 \mathrm{HP}$ negative patients with gastric UBT showed the presence of urease activity in the mouth. We conclude that: $1 .{ }^{14} \mathrm{C}$-urea in quick dissolved capsule is a convenient, non-invasive test for detection of gastric $\mathrm{Hp}$ with accuracy and reproducibility equal to those of gold standards; 2 . feeding does not affect the accuracy of the test; 3 . the results can be analyzed within 10-15 min locally or at a remote site; 4 . orally applied liquid ${ }^{14} \mathrm{C}$-urea may lead to false positive results due to oral urease activity.

\section{C:06 1 HOUR RAPID UREASE TESTS: ACCURACY AND ECONOMIC IMPACT}

N. Vakil, T. Puetz, J. Robinson, S. Phadnis, B. Dunn. Univ of Wisconsin, Milwaukee WI USA

A new generation of rapid urease tests allow test results to be read in 1 hour and less. The aim of this study was to compare a 1 hour rapid urease test to the CLO test, a standard rapid urease test. Methods: 71 patients undergoing upper endoscopy were studied. A single antral biopsy was obtained for the CLO test and another for the Pyloritek test (a new $1 \mathrm{hr}$ rapid urease test). The CLO-test was read at 24 hours by an observer blinded to the results of the Pyloritek assay read at 1 hour. Discordant results were verified by culture. Results: Mean \pm SEM. There were 18 males and 53 females and the mean age was $53 \pm 17$ years. 32 patients had a positive CLO test and 39 had a negative test. Of the 32 patients with positive CLO tests at 24 hours, 31 were positive by the Pyloritek-II test at 1 hour. There was 1 discordant result- a negative Pyloritek test and a positive CLO test. Culture demonstrated growth of $H$. pylori. The $\kappa$ value, a measure of the reliability of the Pyloritek compared to the CLO test was 0.969 , demonstrating a high degree of reliability. In our study, $41 \%$ of the positive assays with the Pyloritek assay were obviously positive in less than 5 minutes. The cost of the 2 tests is the same. In our laboratory, patients are discharged approximately 60 minutes after uncomplicated upper endoscopy and therefore must return for the results of the CLO test or must be prescribed treatment on the telephone the following day, while patients tested with the Pyloritek test can be prescribed treatment before leaving the hospital. Average and marginal cost-effectiveness analysis therefore strongly favored the Pyloritek test. The marginal cost-effectiveness was \$528-2968 depending on the strategy used by physicians to address the results of a CLO test (return office visit or telephone call). Conclusions: 1. The Pyloritek test (1 hr) and the CLO test (24 hrs) are comparable with regard to detection of urease activity. The Pyloritek assay is read at 1 hour allowing antibiotic therapy to be prescribed to infected patients at the time of discharge from the endoscopy laboratory. Eliminating follow-up telephone calls/office visits to discuss the results of $\mathrm{H}$. pylori testing reduces costs substantially.

\section{C:07 COMPARISON BETWEEN EIA (HM-CAP) AND RAPID} (FleXSUre ${ }^{\oplus}$ HP) METHODS TO DETECT SERUM H. PYLORI ANTIBODY IN 1147 ASYMPTOMATIC CHILDREN

Y. Elitsur, C. Neacee, J. Peacock. Department of Pediatrics, Pediatric GI Division, Marshall University, Huntington, WV., USA

Serologic detection of HP antibody in children has been approved as a screening tool to investigate the acquisition of HP infection. The HM-
CAP (high molecular weight Cell Associated Protein) antigen has been incorporated into two commercially availabl assay kits to detect serum HP antibody, namely the HM-CAP EIA and FlexSure ${ }^{\circledR}$ HP rapid test. Aim: To compare FlexSure HP test with EIA method to detect the prevalence of HP infection in asymptomatic children from WV. Methods: 1147 coded serum samples were sent to SmithKline Diagnostics, Inc. and Enteric Product Inc. Laboratories for FlexSure ${ }^{\circledR} \mathrm{HP}$ and EIA tests, respectively. Results: Concordance between methods was found in 1019 (90\%) while discordance was found in $107(10 \%)$ samples. 21 samples were inconclusive by EIA and were discard from our calculation. Compared to EIA test, FlexSure ${ }^{\circledR}$ HP sensitivity and specificity were $83.4 \%$ and $90.5 \%$, respectively. Conclusion: FlexSure ${ }^{\circledR}$ HP method is a comparable and faster than HM-CAP EIA method to detect serum HP antibody in children. FlexSure ${ }^{\circledast}$ HP may be used as an office based screening test to detect the acquisition of HP infection in children. (Funded in part by SmithKline Diagnostics Inc. San Jose, CA)

\section{C:08 A SIMPLIFIED PROTOCOL WITHOUT FASTING AND TEST MEAL IN THE ${ }^{13} \mathrm{C}$-UREA BREATH TEST FOR THE DIAGNOSIS OF HELICOBACTER PYLORI}

W.M. Wang, C.M. Jan, L.T. Chen, D.C. Wu, D.S. Perng, Y.C. Su, C.S. Liu, C.F. Peng, H.J. Ding, S.C. Lee ', C.Y. Chen. Kaohsiung Medical College, Kaohsiung, Taiwan; ' ${ }^{1}$ Institute of Nuclear Energy Research, Tao Yuan, Taiwan, R.O.C.

The aim of this study was to assess the availability of non-fast and without test meal in ${ }^{13} \mathrm{C}$-UBT for the diagnosis of $\mathrm{H}$. pylori infection. One hundred and five consecutive patients who received endoscopic examination were studied. All of them received endoscopic biopsies for urease test, culture and histopathology to detect $\mathrm{H}$. pylori infection. Every patient received the ${ }^{13} \mathrm{C}$-UBT under the following four conditions: Test I) fasting state with test meal (100 ml fresh milk); Test II) non-fast (taking usual food), bu with test meal; Test III) fasting state without test meal; Test IV) non-fast and without test meal. The excess $\delta^{13} \mathrm{CO}_{2}$ were calculated via the breath samples which were collected at 15 and 30 minutes after ingestion of ${ }^{13} \mathrm{C}$-urea. There were $63 \mathrm{H}$. pylori positive and 42 negative patients in this study. The mean $+3 S \mathrm{SD}$ of excess $\delta^{13} \mathrm{CO}_{2}$ values of $\mathrm{H}$. pylori negative patients was used as a cut-off value in each test. The result of the test I had a perfect correlation with the gold standard. The sensitivity of the test II, III, and IV at 15 -minute detecting time were $100 \%, 98 \%$ and $98 \%$, and the specificity of those were $98 \%, 100 \%$, and $95 \%$, respectively. Conclusions: For the clinical diagnosis of $\mathrm{H}$. pylori infection, non-fast, without test meal and detection at 15 minutes in ${ }^{13} \mathrm{C}$-UBT is available in mass survey or epidemiological study.

\section{C:09 DIAGNOSTIC VALUE OF A COMMERCIAL IgG ENZYME-LINKED IMMUNOSORBENT ASSAY (ELISA) KIT FOR HELICOBACTER PYLORI INFECTION DIAGNOSIS}

C. Martín de Argila, D. Boixeda, R. Cantón, S. Valdezate, N. Mir, J. Gisbert, L. de Rafael. "Ramón y Cajal" Hospital, Madrid, Spain

Enzyme-linked immunosorbent assays (ELISAs) are considered good noninvasive methods to diagnose $H$. pylori infection. The aim of this study was to evaluate the clinical usefulness of a commercial IgG $H$. pylori antibody test kit.

Methods: A total of 400 patients attended at the Endoscopy Unit because of symptoms attributable to the upper gastrointestinal tract were studied. At endoscopy, multiple biopsies from gastric antrum and gastric body were obtained for histology and culture. H. pylori was diagnosed if culture was positive in at least one of the biopsy samples obtained. Ten milliliters of venous blood were collected at the time of endoscopy for serological assessment. Serum samples were analyzed for $H$. pylori by a quantitative commercial IgG ELISA, based on an acid glycine extract: Helico G, Porton, Cambridge, UK. The test was performed in duplicate according to the manufacturer's instructions and by the same person. Results were evaluated on the basis of different cut-off values.

Results: In the study population, $89.8 \%$ of the patients were $H$. pylori positive (by culture). The serology results were as follows:

\begin{tabular}{rlllll}
\hline Cut-off & Sensitivity (\%) & Specificity (\%) & PPV (\%) & NPV (\%) & LR \\
\hline $8 \mathrm{U} / \mathrm{ml}$ & 98.3 & 53.7 & 94.9 & 78.6 & 2.1 \\
$10 \mathrm{U} / \mathrm{ml}$ & 97.2 & 85.4 & 98.3 & 77.8 & 6.6 \\
$11 \mathrm{U} / \mathrm{ml}$ & 94.7 & 85.4 & 98.3 & 64.8 & 6.4 \\
\hline
\end{tabular}

PPV = Positive predictive value; NPV = Negative predictive value; $L R=$ Likelihood ratio. 0.96

The area under the receiver operator characteristic (ROC) curve was

Conclusions: This study confirms the diagnostic efficiency of this IgG commercial ELISA in detecting $H$. pylori infection. According to the man- 
ufacturer, $10 \mathrm{U} / \mathrm{ml}$ is the most appropriate cut-off value. The competitive cost of this technique and the fact that it is non-invasive render this method an optimum tool to study $H$. pylori infection in large population groups.

\section{C:10 DIAGNOSTIC VALUE OF A COMMERCIAL IgA ENZYME-LINKED IMMUNOSORBENT ASSAY (ELISA) KIT FOR HELICOBACTER PYLORI INFECTION DIAGNOSIS}

C. Martín de Argila, D. Boixeda, R. Cantón, N. Mir, S. Valdezate, J.P. Gisbert, L. de Rafael. "Ramón y Cajal" Hospital, Madrid, Spain

Enzyme-linked IgG immunosorbent assays (ELISAs) are good noninvasive methods to diagnose $H$. pylori infection, but scarce information are available on IgA ELISAs. The aim of this study was to evaluate the clinical usefulness of a commercial IgA $H$. pylori antibody test kit.

Methods: A total of 400 patients attended at the Endoscopy Unit because of symptoms attributable to the upper gastrointestinal tract were studied. At endoscopy, multiple biopsies from gastric antrum and gastric body were obtained for histology and culture. H. pylori was diagnosed if culture was positive in at least one of the biopsy samples obtained. Ten milliliters of venous blood were collected at the time of endoscopy for serological assessment. Serum samples were analyzed for $H$. pylori by a semiquantitative commercial IgA ELISA, based on purified specific antigens: G.A.P. Test IgA. Bio-Rad, Italy. The test was performed in duplicate according to the manufacturer's instructions and by the same person. Results were evaluated on the basis of different cut-off values.

Results: In the study population, $89.8 \%$ of the patients were $H$. pylori positive (by culture). The serology results were as follows:

\begin{tabular}{rlllll}
\hline Cut-off & Sensitivity (\%) & Specificity (\%) & PPV (\%) & NPV (\%) & LR \\
\hline $8 \mathrm{U} / \mathrm{ml}$ & 98.3 & 34.1 & 92.9 & 70 & 1.5 \\
$10 \mathrm{U} / \mathrm{ml}$ & 96.4 & 80.5 & 97.7 & 71.7 & 4.9 \\
$11 \mathrm{U} / \mathrm{ml}$ & 94.2 & 80.5 & 97.7 & 61.1 & 4.8 \\
\hline
\end{tabular}

$\mathrm{PPV}=$ Positive predictive value NPV $=$ Negative predictive value LR $=$ Likelihood ratio.

The area under the receiver operator characteristic (ROC) curve was 0.9 .

Conclusions: This study confirms the usefulness of this IgA commercial ELISA in detecting $H$. pylori infection. According to the manufacturer, $10 \mathrm{U} / \mathrm{ml}$ is the most appropriate cut-off value. The high sensitivity and positive predictive values render this method very useful for screening large populations groups.

\section{C:11 USEFULNESS OF THE COMBINED USE OF IgG AND IgA ELISA METHODS FOR DIAGNOSING HELICOBACTER PYLORI INFECTION}

C. Martín de Argila, D. Boixeda, R. Cantón, N. Mir, S. Valdezate, L. Moreno, J. Gisbert, L. Ruiz del Arbol. "Ramón y Cajal" Hospital, Madrid, Spain

Aim: To determine the diagnostic value of the combined use og IgG and IgA ELISA methods to diagnose $H$. pylori infection.

Methods: A total of 400 patients attended at the Endoscopy Unit because of symptoms attributable to the upper gastrointestinal tract were studied. At endoscopy, multiple biopsies from gastric antrum and gastric body were obtained for histology and culture. H. pylori was diagnosed if culture was positive in at least one of the biopsy samples obtained. Ten milliliters of venous blood were collected at the time of endoscopy for serological assessment. Serum samples were analyzed for $H$. pylori by a commercial IgA ELISA (G.A.P. Test IgA. Bio-Rad, Italy) and a commercial IgG ELISA (HelicoG, Porton, Cambridge, UK). The tests were performed in duplicate according to the manufacturer's instructions and by the same person. Two interpretations were possible: 1) Assumption 1: a serological result was considered positive for $H$. pylori when both methods (IgG and IgA) were positive, and negative when at least one of them was negative; 2) Assumption 2: a serological result was considered positive when at least one of the methods was positive, and negative when both methods were negative. Titres higher than $10 \mathrm{U} / \mathrm{ml}$ were considered positive (following manufacturer's recommendations) for both tests.

Results: In the study population, $89.8 \%$ of the patients were $H$. pylori positive (by culture). The serology results were as follows:

\begin{tabular}{llllll}
\hline Cut-off IgG/IgA & Sensitivity (\%) & Specificity (\%) & PPV (\%) & NPV (\%) & LR \\
\hline $10 / 10 \mathrm{U} / \mathrm{ml}^{*}$ & 94.1 & 85.3 & 98.2 & 62.5 & 6.26 \\
$10 / 10 \mathrm{U} / \mathrm{ml}^{* *}$ & 99 & 80 & 97 & 94 & 4.95 \\
\hline
\end{tabular}

$\mathrm{PPV}=$ Positive predictive value NPV $=$ Negative predictive value $\mathrm{LR}=$ Likelihood ratio; *Assumption 1; **Assumption 2.

Conclusions: 1) The combined use of both serological methods provided more useful information compared with single IgG or IgA determinations. 2) The high specificity and PPV for assumption 1 render both determi- nations very useful when the clinician wishes to accurately know the "true" infection $H$. pylori status. 3) The extremely high sensitivity obtained with the assumption 2 renders this method very useful for screening large population groups.

\section{C:12 H. PYLORI: A COMBINED METHODOLOGY FOR ITS DETECTION}

M. Zubillaga ' , J. Boccio ', M.L. Calcagno ', R. Caro ', A. Mitta ', O. Degrossi ${ }^{2}$, P. Oliveri ${ }^{2}$. ${ }^{1}$ University of Buenos Aires; ${ }^{2}$ German Hospital Several methods are used in the diagnosis of the gastric infection produced by $\mathrm{H}$. pylori: histology, culture, rapid urease test and polymerase chain reaction. None of them can be considered as a reference standard, because the samples are obtained by an endoscopic biopsy, which is focal in nature and it does not represent the whole surface of the stomach. The purpose of this study is to demonstrate that the combined basal gastric transit with the MIN ${ }^{14} \mathrm{C}$ UBT has the advantage of being representative of the whole stomach surface and constitutes a non-aggressive test.

Materials and Methods: 250 determinations with the introduced modification were performed in 150 patients ( 83 women and 67 men). After the ingestion of $11.1 \mathrm{MBq}(300 \mu \mathrm{Ci})$ of ${ }^{99 \mathrm{~m}} \mathrm{Tc}$-sulfur colloid with the addition of $185 \mathrm{kBq}(5 \mu \mathrm{Ci})$ of ${ }^{14} \mathrm{C}$-Urea, a register of the basal gastric transit has been done by imaging the patient with a gamma camera, and samples of the exhaled air were collected at intervals of 5 minutes during all the studied period.

Results: The results show that there is a good correlation between the images obtained and the samples collected. We found that the test has sensitivity of $100 \%$ and a specificity of $89 \%$.

Discussion: The introduced modification was the administration of the ${ }^{14} \mathrm{C}$-Urea together with the ${ }^{99 \mathrm{~m}} \mathrm{Tc}$-sulfur colloid, which is not absorbed in the gastrointestinal tract and which has the great advantage of allowing the visualization of the ${ }^{14} \mathrm{C}$-Urea inside the gastrointestinal tract. By this modification it is possible to determine simultaneously the production of the ${ }^{14} \mathrm{CO}_{2}$ and the place where this process occurs. Due to its nonaggressiveness, this method can be used in epidemiological studies, in areas in which the disease is widely spread.

\section{C:13 RT-PCR IN DIAGNOSIS OF H. PYLORI INFECTION IN CHILDREN}

K. Kostiainen, M. Ashorn, H. Kainulainen. University of Tampere, Institute of Medical Technology, Tampere, Finland

Based on previous results gastritis without $H p$ seems to be common in children. It is not known whether these children are having a latent infection not measurable with the standard techniques. Aim: 1. To develop a RT-PCR method suitable for use in children and compare it with other diagnostic methods of $H p$ detection. 2. To find out whether RT-PCR is able to detect $H p$ colonization in previously $H p$ negative children with gastritis. Methods: Biopsies from the gastric antrum and body of 102 dyspeptic patients (age 3 to 16 yrs, 20 culture- and histology-positive) were examined by using RT-PCR. Gastric biopsies from 16 culturally and histologically $H p$-negative non-symptomatic children without histological gastritis were used as controls. For RT-PCR 518 bp sequence of $H p$ 16S rRNA was used as template for reverse transcription polymerase chain reaction. RT-PCR was carried out with DNA polymerase of Thermus thermophilus that is able to both reverse transcribe and amplify RNA-sequences. This allows the RT-PCR to be carried out in a single-enzyme, single-tube reaction. Results: RT-PCR detected $H p$ in 19 out of 20 culture positive patients (sensitivity 95\%). All biopsies from the 16 control children were PCR negative (specificity $100 \%$ ). The analysis of biopsies from 82 dyspeptic children, of whom $48(58.5 \%)$ had histological gastritis revealed $H p$ in none of the specimens. Conclusions: 1. RT-PCR is a sensitive method (comparable to culture) in the diagnosis of $H p$ infection in children. 2. $H p$-negative gastritis excists commonly in children which had been already previously shown with the methods generally in use.

\section{C:14 HELICOBACTER PYLORI ${ }^{13}$ C-UREA BREATH TEST IS INFLUENCED BY THE GASTRIC BACTERIAL FLORA OF THE PIG}

L. Engstrand, H. Enroth, H. Berglund, M. Bergström, W. Kraaz, P. Tracz, S. Gustavsson. Dept. of Clin. Chem., Huddinge, Sweden; Depts. of Cancerepidemiol., Clin. Microbiol., Pathol. and Surgery, Uppsala, Sweden

Background Since 1987, a pig model has been used for $H$. pylori studies in Uppsala. In 1994, a new kind of specific pathogen free minipig was introduced (Ellegaard Göttingen minipigs, Denmark). The aim of this study was to evaluate the influence of the normal gastrointestinal flora on the 
${ }^{13} \mathrm{C}$-UBT and to characterize other bacteria in the pig stomach that may provide false positive UBT-scores.

Materials and methods Seven pigs were divided into three groups: controls $(\mathrm{n}=2)$, H. pylori $(\mathrm{n}=2)$ and urease-controls $(\mathrm{n}=3)$. Four reference strains and one clinical isolate of $H$. pylori were orally administered to the pigs. $P$. mirabilis, $S$. albus and $P$. aeruginosa were given to the urease-controls. UBT and biopsies for histology, immunohistochemistry, culture and urease activity were obtained from all pigs once a week during five weeks. Changes in the gastrointestinal flora in the urease-control group were also determined after omeprazole treatment. At the end of the study, an extensive topographic mapping of the stomach including an urease activity assay, culture and a histopathological examination were performed.

Results UBT was not specific for $H$. pylori in minipigs. Occasionally, high UBT values were present in minipigs which were never exposed to H. pylori. Omeprazole administration during five days did not significantly change the UBT values. No $H$. pylori organisms were isolated by culture or demonstrated by histology. Our results indicate that other bacteria than $H$. pylori may be responsible for high UBT values and for the problems we had to establish a persistent $H$. pylori infection.

Discussion The human gastrointestinal flora is affected when patients are treated with acidsuppressors, antibiotics, after gastric surgery, in cancerpatients and in immunocompromized patients. To sum up, urease producing bacteria in the stomach, and in the duodenum, may influence the UBT values and give false positive $H$. pylori scores, at least in minipigs.

\section{C:15 THE HELISAL TEST - AN ASSESSMENT OF READABILITY AND PERFORMANCE}

M.A. Stone, J.F. Mayberry, A.C.B. Wicks, S. Livsey, M. Stevens, A. Swann, R.J. Robinson. Leicester General Hospital and Leicester Royal Infirmary Leicester, UK

Aims: To evaluate the Cortecs Helisal Rapid Blood test for readability of results and for age specific and overall performance.

Methods: Patients attending for endoscopy were recruited for $H$. pylori testing with the Helisal Rapid Blood test, plus 4 reference tests (antral culture, CLO test and histology, plus Launch Diagnostics Premier serum ELISA). Antibiotics or proton pump inhibitors in the previous week, gastric surgery and previous eradication therapy were exclusion criteria. Consecutive complete results for 100 patients were analysed overall and in patients aged under and over 45 years. Two or more reference tests positive $(n=42)$ was taken as a gold standard positive; all results negative as negative $(\mathrm{n}=49)$. Nine patients were deemed to have equivocal $H$. pylori status and results were analysed twice treating these as positive or negative, giving a performance range. For calculating performance, a positive-negative decision was made even where readability of the test was poor, as equivocal results are not specified in the manufacturer's instructions. 96 of the 100 Helisal tests were double-read, blinded; the reading of the person recruiting the patient was used in cases of discrepancy.

Results: Readability $11(11 \%)$ tests were considered difficult to read and in $6(6 \%)$ cases there was a discrepancy between the readings of the two observers.

\begin{tabular}{llll}
\hline Performance & $\begin{array}{l}\text { All pts } \\
(\mathrm{n}=100)\end{array}$ & $\begin{array}{l}\text { Under 45 } \\
(\mathrm{n}=33)\end{array}$ & $\begin{array}{l}45 \text { or over } \\
(\mathrm{n}=67)\end{array}$ \\
\hline Sensitivity (\%) & $92-95$ & $93-100$ & $92-94$ \\
Specificity (\%) & $50-55$ & $68-74$ & $39-43$ \\
PPV (\%) & $58-68$ & $61-72$ & $57-67$ \\
NPV (\%) & $87-94$ & $93-100$ & $81-88$ \\
\hline
\end{tabular}

Conclusions: A notable proportion of tests were deemed unreadable. Sensitivity was good in all ages but specificity was poor, particularly in the older age group. The test could be considered suitable for pre-endoscopy screening of younger patients but may be inappropriate in other situations.

\section{C:16 A STANDARDISED METHOD FOR DETERMINING $H$. PYLORI INFECTION DENSITY AT ENDOSCOPY}

M.A. Asante, P. Patel, A. Verma, L. Ballam, H. Ahmed, C. Finlayson ', M. Mendall, T.C. Northfield. Department of Medicine, St. George's Hospital Medical School, London; ' Department of Histopathology, St. George's Hospital Medical School, London

Background: Patients with H. pylori positive non ulcer dyspepsia on the whole do not benefit from eradication therapy. $H$. pylori infection density is a virulence factor for peptic ulceration; higher in duodenal ulcer patients compared to those with gastritis alone. Identification of $\mathrm{H}$. pylori positive non ulcer dyspeptic patients with high antral infection density may identify a subgroup with high predisposition to peptic ulceration and thus benefit from eradication therapy. There is however no standardized method for determining infection density at the time of endoscopy. Aim: To quantify the $\mathrm{H}$. pylori urease test and determine its relationship to $\mathrm{H}$. pylori infection density; and also to determine the predictive value of this test for duodenal ulcers.

Method: 65 consecutive patients attending for endoscopy were included in the study. 3 antral biopsies were taken with a standard biopsy forcep (19 K, Keymed). One biopsy was placed in a standardized urea solution consisting of $5 \%$ urea with $2 \%(\mathrm{v} / \mathrm{v})$ phenol red, $\mathrm{pH} 7.20 \pm 0.02$. Colour change with time was measured by colorimetery at $550 \mathrm{~nm}$ (OD) at room temperature. Patients were urease positive if colour change developed within 24 hrs. Infection density was scored by histology on a 0-3 scale according to the Sydney classification. Patients were classified as H. pylori positive if either test was positive.

Results: There was a strong correlation between the OD units and infection density at 10 and 15 mins. (Rs $=0.72, p<0.0001 \& R s=0.61$, $p$ $<0.005$ respectively.) A score of $\geq 2$ was taken as high infection density. At 15 mins an OD of 0.250 gave a sensitivity and specificity of $90 \%$ \& $89 \%$ for predicting high infection density and identified all duodenal ulcer patients. It also identified $45 \%$ of non ulcer dyspeptic patients with high infection density.

Conclusions: We have developed a quantitative rapid urease test which can identify patients with higher infection density. It may be useful in identifying non ulcer dyspeptic patients who may benefit from eradication therapy, but this needs checking in a controlled trial.

\section{C:17 LESS SENSITIVITY OF THE ${ }^{13}$ C-UREA BREATH TEST $\left({ }^{13} \mathrm{C}-U B T\right)$ FOR THE DIAGNOSIS OF HELICOBACTER PYLORI} (H.P.) INFECTION BY USING ORANGE JUICE AS TEST DRINK

A. Leodolter, U. v. Arnim, J.E. Domínguez-Muñoz, P. Malfertheiner Department of Gastroenterology, University Magdeburg, Germany

We previously demonstrated that a citric acid solution is a better test meal for the ${ }^{13} \mathrm{C}$-UBT than the frequently used semiliquid or fatty meals in terms of ${ }^{13} \mathrm{CO}_{2}$ recovery, accuracy and cost. In the last time few groups use the better tasting orange juice instead of citric acid despite accuracy data are lacking. Aim of this study was to verify the accuracy of the ${ }^{13} \mathrm{C}$-UBT by using orange juice as test drink

Methods 32 patients (18 male, 14 female, age: 23-65 y) suffering from dyspeptic symptoms were studied. H.p. infection was tested by histological, microbiological and serological examination. In all patients ${ }^{13} \mathrm{C}$-UBT with two different test meals on two consecutive days was performed. After collecting basal breath samples $200 \mathrm{ml} 0.1 \mathrm{~N}$ citric acid or $200 \mathrm{ml}$ orange juice was administered in a randomized order. Both solutions included $75 \mathrm{mg}{ }^{13} \mathrm{C}$-urea. The ${ }^{13} \mathrm{CO}_{2} /{ }^{12} \mathrm{CO}_{2}$ ratio in the basal breath sample was compared with that of samples collected at 15, 30, 45, 60 minutes after the administration of ${ }^{13} \mathrm{C}$-urea. Results are expressed as "Delta over base" (DOB) values. A positive test is defined by a maximal DOB $>4 \%$. Also the total ${ }^{13} \mathrm{CO}_{2}$ recovery over 60 min expressed as "area under curve" (AUC) and the time to maximal DOB were calculated. Statistical analysis was performed by the Wilcoxon signed-rank test for paired data.

Results. 16 of 32 patients (50\%) were infected with HP. Analysis of results for $H . p$. positiv:

\begin{tabular}{llll}
\hline $\mathrm{n}=16$ & Citric acid & Orange juice & Wilcoxon test \\
\hline DOB max. (\%o) & $40.7 \pm 8.5$ & $25.9 \pm 5.0$ & $p<0.05$ \\
AUC & $1587 \pm 300$ & $967 \pm 190$ & $p<0.01$ \\
Tmax (min) & $23.0 \pm 9.9$ & $20.7 \pm 9.8$ & n.s. \\
\hline
\end{tabular}

Two patients with H.p. infection were not detected by using orange juice as a test drink (sensitivity $87 \%$ ), but by using citric acid (sensitivity $100 \%$ ). Specificity was $100 \%$ using both test drinks.

Discussion. The use of orange juice instead citric acid as test drink in the ${ }^{13} \mathrm{C}$-UBT is associated with a lost of sensitivity for the diagnosis of $H . p$. infection. This is due to a lower ${ }^{13} \mathrm{CO}_{2}$ recovery by using orange juice as compared with citric acid solution.

\section{C:18 EVALUATION OF A NEW EIA METHOD (MICRO PLATE HELICOBACTER IGG) FOR SEROLOGICAL DIAGNOSIS OF $H$. PYLORI IN CHILDREN}

M. López-Brea, I. Sánchez, D. Domingo, T. Alarcón, J.C. Sanz. Hospital de la Princesa, Madrid, Spain

Purpose: To evaluate a new quantitative EIA method (Micro-Plate Helicobacter IgG: Boehringer Mannheim) for diagnosis of $H$. pylori (Hp) infection in children.

Methods: 216 sera samples from 216 endoscopied children (mean age $9.63 \pm 3.68$ years) were studied. Diagnosis of infection was established according to culture (C) and histological (H) standard methods. Sera samples (obtained at the moment of the endoscopy) were tested according to the manufacturer's recommendations. Six serological cut-off $(2,1,0.9$, $0.8,0.7$ and $0.6 \mathrm{Units} / \mathrm{ml}$ ) were employed. 
Results: Diagnosis was confirmed in 117 patients (mean age $10.2 \pm$ 3.9 years) and excluded in 99 (age $8.9 \pm 3.1$ years). The results in terms of diagnostic accuracy (DA), sensitivity (SE) and specificity (ES) of each serological cut-off were:

\begin{tabular}{lllll}
\hline Cut-off & DA & SEN & SPE & \\
\hline$\geq 2$ & 58.7 & 24.7 & 98.9 & $\mathrm{p}=0.0000005$ \\
$\geq 1$ & 74.5 & 60.6 & 90.9 & $\mathrm{p}<0.0000000$ \\
$\geq 0.9$ & 75.4 & 68.3 & 83.8 & $\mathrm{p}<0.0000000$ \\
$\geq 0.8$ & 76.8 & 73.5 & 80.8 & $\mathrm{p}<0.0000000$ \\
$\geq 0.7$ & 76.8 & 78.6 & 74.7 & $\mathrm{p}<0.0000000$ \\
$\geq 0.6$ & 70.8 & 79.4 & 60.6 & $\mathrm{p}<0.0000000$ \\
\hline
\end{tabular}

Conclusions: The best DA level (proportion of correct results among all results) were obtained when a decreased cut-off point $(\geq 0.8$ or $\geq$ 0.7 ) was considered. Although the recommended cut-off (positivity $\geq 1$ $\mathrm{U} / \mathrm{ml}$ ) shows a good specificity, the use of a modified cut-off (positivity $\geq$ $0.8 \mathrm{U} / \mathrm{ml}$ or $\geq 0.7 \mathrm{U} / \mathrm{ml}$ ) seems to be preferable in order to improve the sensitivity for diagnosis in children.

\section{C:19 SIMPLIFICATION OF AN OPTIMAL ${ }^{13}$ C-UREA BREATH TEST $\left({ }^{13} \mathrm{C}\right.$-UBT) FOR THE DIAGNOSIS OF HELICOBACTER PYLORI (H.P.) INFECTION}

J.E. Domínguez-Muñoz, A. Leodolter, U. v. Arnim, P. Malfertheiner. Dpt. Gastroenterology, University Hospital Magdeburg, Germany

The ${ }^{13} \mathrm{C}$-UBT was previously optimized by giving a citric acid solution as test drink $10 \mathrm{~min}$ before the administration of ${ }^{13} \mathrm{C}$-urea. In order to simplify the test, we evaluated whether it is possible to administrate the substract solved in the test drink without loosing diagnostic accuracy.

Methods 40 dyspeptic patients (22 male, 18 female, age: 13-75 y) were studied. H.p. infection was tested by histological and microbiological examination. A ${ }^{13} \mathrm{C}$-UBT was performed on two consecutive days by giving in randomized order $200 \mathrm{ml} 0.1 \mathrm{~N}$ citric acid solution either 10 min previous or simultaneous to $75 \mathrm{mg}{ }^{13} \mathrm{C}$-urea. The ${ }^{13} \mathrm{CO}_{2} /{ }^{12} \mathrm{CO}_{2}$ ratio was measured before and $15,30,45$ and $60 \mathrm{~min}$. after administration of ${ }^{13} \mathrm{C}$-urea. Results are expressed as "Delta over base" (DOB) values (\%o) (H.p. positive if DOB max. $>4 \%$ ). Also the total ${ }^{13} \mathrm{CO}_{2}$ recovery over 60 min expressed as "area under curve" (AUC) and the time to maximal DOB (Tmax) were calculated.

Results 20 patients (50\%) were infected with H.p.

\begin{tabular}{llll}
\hline $\begin{array}{l}\text { H.p. } \\
(\mathrm{n}=20)\end{array}$ & $\begin{array}{l}\text { Test drink and } \\
10 \text { min appart }\end{array}$ & $\begin{array}{l}{ }^{13} \mathrm{C} \text {-urea } \\
\text { simultaneously }\end{array}$ & $\begin{array}{l}\text { paired } \\
\text { Wilcoxon test }\end{array}$ \\
\hline DOB max. & $28.1 \pm 3.2$ & $30.6 \pm 3.7$ & n.s. \\
AUC & $1270 \pm 158$ & $1390 \pm 179$ & n.s. \\
Tmax (min) & $34 \pm 3$ & $35 \pm 3$ & n.s. \\
\hline
\end{tabular}

Specificity was $100 \%$ with both methods. The ${ }^{13} \mathrm{C}$-urea was stable in citric acid solution at room temperature over at least two weeks.

Discussion. The ${ }^{13} \mathrm{C}-\mathrm{UBT}$ for the diagnosis of $H$. pylori infection can be substantially simplified without loosing diagnostic accuracy by giving the substract together with the test drink.

\section{C:20 UTILITY OF A WESTERN BLOT METHOD (HELICOBLOT 2.0)}

M. López-Brea, T. Alarcón, D. Domingo, I. Sánchez, J.C. Sanz. Hospital de la Princesa, Madrid, Spain

Purpose: To evaluate the utility of a western blot method for the diagnosis of $H$. pylori $(\mathrm{Hp})$ infection in children.

Methods: Forty-eight infected patients (culture+ or histology+) (mean age $10.1 \pm 3.4$ years) and 48 non infected children (culture- and histology-) (mean age $9.3 \pm 3.1$ years) were studied. Serum from each patient was obtained at the moment of the endoscopy. The specific serological IgG against some Hp proteins (19.5, 26.5, 30.5, 35.5, 89 and 116 $\mathrm{kD}$ ) was detected by using a blotting method (Helicoblot 2.0, Genelabs). In order to obtain different serological diagnostic levels, several criteria were considered: manufacturer's recommended criteria (MRC) (positivity for 1 of the 35,89 or $116 \mathrm{kD}$ bands or positivity for 2 of the $19,26.5$ or 30 $\mathrm{kD}$ bands); positivity according to the number of bands and reactivity for 19.5\&26.5 $\mathrm{kD}$ combined bands (+result: positivity for at least 1 of the 2 bands and -result: negativity for the 2).

Table 1

\begin{tabular}{llll}
\hline & \% SE & \% SP & \% DA \\
\hline (MRC) & 93.75 & 83.33 & 88.54 \\
$26.5 \mathrm{kD}$ & 83.33 & 95.83 & 89.58 \\
$\geq 2$ bands+ & 87.50 & 95.83 & 91.66 \\
$19.5 \& 26.5 \mathrm{kD}$ & 85.41 & 95.83 & 90.62 \\
\hline
\end{tabular}

Results: The best results according to the diagnostic accuracy (DA) in terms of sensitivity (SE) and specificity (SP) are presented in Table 1.

Conclusions: Recommended criteria reached a good level of accuracy. However in order to improve the specificity, other criteria such as reactivity for $\geq 2$ bands or the combined use of 19.5 and $26.5 \mathrm{kD}$ bands could be considered in children.

\section{C:21 ANTIBODY RESPONSE TO HELICOBACTER PYLORI ANTIGENS: SENSITIVITY AND SPECIFITY OF IGG-ELISA AND AN H. PYLORI SPECIFIC IMMUNO-BLOT SYSTEM}

U. Schmidt-Wittig, U. Platzer, G. Illies, M. Nilius, A. Hackelsberger, P. Malfertheiner. Dept. Gastroenterology, Hepatology and Infect. Diseases Otto-von-Guericke-University Magdeburg, Germany

Background: $\mathrm{H}$. pylori infection is either detected by invasive means using the urease test (HUT), histology, culture or noninvasively by ${ }^{13} \mathrm{C}$-urease breath test or serology. Antibody response may be determined either by ELISA or by immunoblot technique. Aim of our study was to investigate the sensitivity and specifity of a new immunoblot system in comparison to other methods.

Methods: 66 patients with chronic gastritis (CG), 29 with gastric (GU) and 25 patients with duodenal (DU) ulcer were tested for presence of H. pylori infection by HUT, histology, IgG-ELISA (Biorad, Germany) and a new commercially available immunoblot system (BAG-Pylori-Blot, BAG Germany) based upon $\mathrm{H}$. pylori specific antigens. For evaluation of IgG-ELISA and immunoblot 66 patients with positive and 43 patients with negative HUT and histology served as reference for sensitivity and specifity, respectively, as well as for positive (PPV) and negative (NPV) predicted value.

Results (see tables): Both methods showed highest sensitivity in DU sera, while specifity was best in CG patients. In most of the calculated parameters immunoblot results exceed all those of IgG-ELISA.

\begin{tabular}{llllll}
\hline & & Sensitivity & Specifity & PPV & NPV \\
\hline ELISA & CG & $77 \%$ & $68 \%$ & $70 \%$ & $56 \%$ \\
& GU & $76 \%$ & $38 \%$ & $76 \%$ & $37.5 \%$ \\
& DU & $94 \%$ & $14 \%$ & $74 \%$ & $50 \%$ \\
Blot & CG & $81 \%$ & $68 \%$ & $71 \%$ & $58 \%$ \\
& GU & $81 \%$ & $38 \%$ & $77 \%$ & $43 \%$ \\
& DU & $94 \%$ & $28 \%$ & $77 \%$ & $66 \%$ \\
\hline
\end{tabular}

Conclusion: Tested immunoblot-system represents a suitable alternative for IgG-ELISA with even higher sensitivity and specifity and implies the possibility of screening for specific antigens of infecting $\mathrm{H}$. pylori strains in patients.

\section{C:22 NON-INVASIVE DIAGNOSIS OF H. PYLORI INFECTION IN CHILDREN BY COMBINED USE OF IgG AND IgA SEROLOGY AND UREA BREATH TEST}

J.C. Sanz, T. Alarcón, J. Martínez, D. Domingo, M. López-Brea. Hospital de la Princesa, Hospital Niño Jesús, Madrid, Spain

Purpose: To determine the usefulness of the combination of non-invasive procedures (IgG and IgA serology and urea breath test) for the diagnosis of $H$. pylori infection in children.

Methods: Two groups of patients submitted to gastroscopy and urea breath test (European method; cut-off ${ }^{13} \mathrm{C} \geq 5$ per 1,000) were studied: 22 $\mathrm{Hp}$ infected patients (culture+ or histology+) (mean age $9.6 \pm 3.7$ years) and 7 non-infected children (culture- and histology-) (mean age $8.8 \pm$ 2.9 years). Serum from each patient was obtained at the moment of the endoscopy and the urea breath test (UBT). The detections of IgG and IgA were carried out by using quantitative EIAs (EIA-G and EIA-A Pyloriset; Orion Diagnostica). A 200 Pyloriset titer was used as cut-off.

Results: The results of UBT, IgG, IgA and combinations of two noninvasive methods (positivity at least one of the two tests positive and negativity the two tests negative) referred to culture and histology and expressed as sensitivity (SE), specificity (SP) and diagnostic accuracy (DA) are presented in the table.

\begin{tabular}{lclcl}
\hline & SE & SP & DA & \\
\hline UBT & 90.09 & 100 & 93.1 & $\mathrm{p}=0.0000231$ \\
IgG & 81.81 & 100 & 86.2 & $\mathrm{p}=0.0002114$ \\
IgA & 45.45 & 100 & 58.62 & $\mathrm{p}>0.05$ \\
UBT-IgG & 100 & 100 & 100 & $\mathrm{p}=0.0000006$ \\
UBT-IgA & 90.09 & 100 & 93.1 & $\mathrm{p}=0.0000231$ \\
IgG-IgA & 81.81 & 100 & 86.2 & $\mathrm{p}=0.0002114$ \\
\hline
\end{tabular}

Conclusions: Combined results of UBT and IgG reached a excellent diagnostic accuracy. The detection of IgA show not advantage even combined with the other tests. 


\section{C:23 COMPARATIVE EVALUATION OF CULTURE, RAPID UREASE TEST, HISTOLOGY, POLYMERASE CHAIN REACTION AND SEROLOGY FOR THE DIAGNOSIS OF H. PYLORI INFECTION}

A. Novillo, M. Tokumoto, C. Mari Campo, V. Ybarra, J. Vogel, E. Velasco, R. Viacava, A. Roseto, J. Adami. Sanatorio Modelo de Ouilmes, Laboratorio de Análisis Especializados, Sociedad Argentino-Europea de Medicina Molecular, Buenos Aires, Argentina

The aim of this study was to investigate the efficiency of different methods to establish infection with $\mathrm{H}$. pylori, in patients with gastroduodenal symptoms.

Serum and biopsies specimens (antrum, corpus and duodenum), were obtained from 131 patients. The results were positive in $68 \%, 66 \%, 68 \%$, $66 \%$ and $66 \%$ according to the results of rapid urease test (RUT), culture (C), polymerase chain reaction (PCR), histology (HS) and elisa PYLORISTAT test kit Biowhittaker (EIA). The infection state was considered as positive or negative if at least 3 of 5 test agreed. In this respect 126 patients could be classified as 90 positive and 36 negative. Among the remaining 5 patients who were positive for only 2 tests, were not included in the following analisis. The table below summarizes the results according to the H. pylori infection state.

\begin{tabular}{lrrllc}
\hline & RUT & C & PCR & HS & EIA \\
\hline \% SENS & 99 & 95 & 93 & 90 & 95 \\
\% SPEC & 100 & 100 & 86 & 83 & 100 \\
\% PVP & 100 & 100 & 94 & 93 & 100 \\
\% PVN & 97 & 90 & 84 & 77 & 90 \\
\hline
\end{tabular}

In conclusion the RUT was the most reliable and rapid test for the diagnosis of $\mathrm{H}$. pylori infection. The Pylori-Stat test is also a useful screening test and would help to reduce the necessity for invasive endoscopic procedures.

\section{C:24 DEVELOPMENT OF A CONFIRMATORY TEST FOR HELICOBACTER PYLORI 16S RDNA PCR PRODUCTS}

L.V. Pallesen, K.A. Krogfelt. Statens Serum Institut, Copenhagen, Denmark

Aim: To develop a simple, specific and rapid colorimetric hybridization assay for the detection of amplified DNA.

Methods: The assay is based on the semisolid hybridisation between a solid-phase coupled capture probe and a biotinylated detection probe. The capture probe is covalently bound to a polystyrene microwell surface. Hybridization is performed for one hour at $50^{\circ} \mathrm{C}$. Detection probe is visualized by binding of an alkaline phosphatase conjugated anti-biotin antibody followed by a reaction with pNPP substrate. The sensitivity of the assay was enhanced by coupling repetitive biotin units to the detection probe.

Results: The method was applied to the detection and confirmation of a 542 bp 16S rDNA fragment generated by PCR of $H$. pylori DNA extracted from human gastric biopsies. The sensitivity of the assay enables the detection of positive sample not detected by ethidiumbromide stained agarose gels. Amplification of samples containing complex DNA often results in multible bands. The assay allows confirmation of the presence of $H$. pylori DNA in the biopsy without repeating nor the DNA extraction from the tissue neither the PCR-protocol. The total process time for the confirmation assay is two hours.

Conclusion: The assay is designed in a microwell format enabling the processing of multible samples simultaneously. False positive results due to multiple bands on the gel are avoided as are false negative results due to the low detection limit of the assay.

\section{C:25 DEVELOPMENT AND EVALUATION OF A COMPETITIVE INTERNAL CONTROL DNA FRAGMENT IN A PCR-PROTOCOL FOR DETECTION OF HELICOBACTER PYLORI}

A.C.E. Thoreson ${ }^{1}$, M. Borre ${ }^{1}$, L.P. Andersen ${ }^{2}$, F. Jørgensen ${ }^{3}$ S. Kiilerich ${ }^{3}$, J. Scheibel ${ }^{4}$, J. Rath ${ }^{3}$, K.A. Krogfelt ${ }^{1} .{ }^{1}$ Statens Seruminstitut, ${ }^{2}$ National University Hospital, ${ }^{3}$ Glostrup University Hospital, ${ }^{4}$ Herlev County Hospital, Copenhagen, Denmark

Aim: To develop a simple, sensitive and specific PCR protocol for defection of false negative results due to inhibition of PCR reaction.

Methods: ACT1 and ACT2 primers amplifying 16S rDNA result in a 542 bp fragment. The internal control consists of a 2131 bp foreign DNA fragment flanked by the target sequences of the two primers. Direct PCR was performed on human gastric biopsies with addition of the internal control. Furthermore, biopsies from each patient were cultured and examined histologically for the presence of HLOs. All tests were performed as blinded tests.

Results: Biopsies from 101 unselected patients with gastric symptoms were tested. When the internal control was not amplified, PCR was repeated on 10-fold serial dilutions of the extracted DNA. By use of the internal control it was shown that $12 \%$ of the first PCR results were false negative. Concordant results were found in 37 and 41 samples as negative and positive respectively. In nine biopsies $H$. pylori DNA was detected while culturing and microscopy for HLO were negative. Culturing was seen to be the least sensitive method since 10 samples were negative, while found positive in the two other tests.

Conclusion: Use of an internal control while performing PCR on human tissues is important for the prevention of false negative results. Results of culture and histology were considered Gold Standard. 16S rDNA based PCR protocol improved sensitivity in the detection of $H$. pylori in human biopsies. A total of $60 \%$ of the samples were positive by PCR while $55 \%$ were positive by either culture and/or histological examination.

\section{C:26 BM-TEST HELICOBACTER PYLORI FOR WHOLE-BLOOD SAMPLES: AN EASY AND RAPID DETECTION METHOD FOR H. PYLORI INFECTION}

H. Enroth, R. Rigo, K. Hultén, L. Engstrand. Depts. of Clin. Microbiol, and Cancerepidemiol., Uppsala, Sweden

Introduction As the market is flooded with new diagnostic kits for rapid $H$. pylori detection, there is an urgent need for prospective evaluation studies. The aim of this study was to evaluate the sensitivity and specificity of the wholeblood BM-test Helicobacter pylori in patients with symptoms from the upper gastrointestinal tract and gastric cancer patients.

Materials and methods Patients were included at endoscopy. Biopsies were cultured for $H$. pylori and immunohistochemically stained. Serum and wholeblood was collected for analysis with both ELISA and rapid whole blood test ( $\mu$ PLATE Helicobacter IgG and BM-test Helicobacter pylori, Boehringer Mannheim). Two groups of patients were tested: gastric cancer patients $(n=48)$ and patients with other GI symptoms $(n=144)$. Serology was determined as the gold standard for $H$. pylori infection in the cancer patient group. Culture and/or histology were used as standard for the other group of patients. Sensitivity/specificity of the BM-test Helicobacter pylori were calculated for both groups independently and together.

Results The sensitivity/specificity of the BM-test Helicobacter pylori in the gastric cancer group was $91 \%$ and $71 \%$ and in the GI symptom group $96 \%$ and $83 \%$ respectively. When both groups were calculated together and culture/histology were used as standard, the sensitivity as well as the specificity for the BM-test Helicobacter pylori decreased to $95 \%$ for sensitivity and $72 \%$ for specificity. Culture and histology results corresponded well with ELISA and BM-test Helicobacter pylori in the GI symptom group, but not in the gastric cancer group.

Discussion The rapid BM-test Helicobacter pylori is an easy screening test with high sensitivity/specificity in patients with GI symptoms other than gastric cancer. Overall, the BM-test Helicobacter pylori results corresponded well with ELISA, culture and histology. However, there was a high number of false negative cancer patients, as determined by culture and histology, which is in accordance with previous studies.

\section{C:27 PERCENTAGE CHANGES IN SERUM PEPSINOGENS ARE USEFUL AS INDICES OF ERADICATION OF H. PYLORI}

T. Furuta, E. Kaneko, S. Baba, H. Arai, H. Futami. Hamamatsu University School of Medicine, Hamamatsu, Japan

Establishment of a precise diagnostic method for $H$. pylori is of great value. The aim of this study was to establish a new method for precisely judging the eradication of this bacteria

We measured serum pepsinogen (PG) I and PG II levels in 105 cases of peptic ulcer with $H$. pylori infection before and after anti- $H$. pylori treatment, determined percentage changes in serum PG I/PG II ratios before and one month after the treatment, and established cut-off values for them in order to distinguish success from failure of $H$. pylori eradication. Cut-off values for percentage changes in serum PG I/PG II ratios were tentatively set to be $+40 \%,+25 \%$, and $+10 \%$ when the serum PG I/PG II ratios before the treatment were less than 3.0 , not less than 3.0 but less than 5.0, and not less than 5.0, respectively. Histology was also studied according to the Sydney System before and after the treatment.

With the use of these cut-off values, the sensitivity, specificity, and validity for determination of eradication of $H$. pylori on the basis of culture, histology, the rapid urease test, and a PCR method were 96.3\%, 98.0\%, and $97.1 \%$, respectively. These cut off values could be applied for both of gastric ulcer and duodenal ulcer. In the group with eradication of $\mathrm{Hp}$, activity of gastritis significantly improved.

Our findings suggest that percentage changes in serum PG I/PG II ratios are useful as indices for distinguishing success from failure in eradication therapy for $\mathrm{H}$. pylori. These changes might reflect improvement of the activity of gastritis caused by $H$. pylori infection. 
4C:28 THE DETECTION OF HELICOBACTER PYLORI - WITH EMPHASIS ON A SENSITIVE CULTURE SYSTEM

J.C. Yang ${ }^{1}$, C.K. Yang ${ }^{2}$, C.T. Shun ${ }^{3}$, J.T. Wang ${ }^{1}$, T.H. Wang ${ }^{1} .{ }^{1}$ Dept. of Internal Medicine, National Taiwan University Hospital, Taipei, Taiwan, ROC; ${ }^{2}$ Dept. of Clinical Pathology, National Taiwan University Hospital, Taipei, Taiwan, ROC; ${ }^{3}$ Dept. of Pathology, National Taiwan University Hospital, Taipei, Taiwan, ROC

The detection of $H$. pylori (Hp) may be interfered when the activity and amount of $\mathrm{Hp}$ is suppressed by anti-Hp therapy. We developed a culture system and compared with the current diagnostic methods. Methods: The study population consisted of 522 patients with gastroduodenal diseases. Some of these patients repeated the endoscopy $4 \approx 6$ weeks after anti-Hp therapy. Totally, 832 endoscopy were performed. Five biopsy specimens were obtained from the gastric antrum: two for culture (using an improved culture system with modified transport and selective culture media and an optimal incubating condition within a glove box), one for CLO test, and two for histology (HE and silver stain). The amount of $\mathrm{Hp}$ was graded from 0 to 4. Blood samples were also collected for serologic test (HEL-p test). The Hp status was considered as positive when (1) at least two of the four tests (pre-treatment) or two of the three tests (post-treatment) were positive; (2) if only one test was positive, the amount of Hp must not be less than grade 2. Results: (1) The pre-treatment survey included 522 sets $(450 \mathrm{Hp}+; 72 \mathrm{Hp}-)$ of specimens. The sensitivity of culture, CLO test, histology and serologic test was $99.1 \%, 92.2 \%, 94.4 \%$ and $91.1 \%$, respectively, and the specificity $100 \%, 98.6 \%, 94.4 \%$ and $95.8 \%$ respectively. (2) The post-treatment survey included 310 sets $(77 \mathrm{Hp}+; 233$ $\mathrm{Hp}-$ ) of specimens. The sensitivity of culture, CLO test, histology became $98.7 \%, 84.4 \%$, and $88.3 \%$, respectively, and the specificity $100 \%, 99.6 \%$, and $94.4 \%$, respectively. Conclusion: The improved culture system is a very sensitive method of detecting $\mathrm{Hp}$, even after anti-Hp therapy. By using this system, we can get the bacterial strains of almost all of Hp positive cases to provide the basic materials for further researches.

\section{C:29 POST-TREATMENT DIAGNOSIS OF H. PYLORI INFECTION BY PCR: A COMPARISON WITH OTHER INVASIVE TECHNIQUES}

E. Godfroid ' , F. Mansy ', A. Fauconnier ', A. Lage ' , C. Deprez ${ }^{2}$, Y. Glupczynski ${ }^{3}$, A. Burette ${ }^{2}{ }^{1}$ Génétique Appliquée, CHU A. Vésale, Brussels; ${ }^{2}$ Nouvelle Clinique de la Basilique, CHU A. Vésale, Brussels; ${ }^{3}$ Montigny-le-Tilleul, Belgium

The aim of the study is to evaluate the post-treatment (4-6 weeks) sensitivity and specificity of the ureC-PCR assay and other diagnostic methods (culture, rapid-urease test (RUT), and histological, examination) for detection of $H$. pylori in antral and corpus biopsies from 118 consecutive patients. Long term follow-up ( $\geq 3$ months) of $H$. pylori status was also available in $70 \%$ of the patients. The comparative results obtained by all the different methods are presented in the following table:

\begin{tabular}{lllll}
\hline PCR & Culture & RUT & Histology & No. of patients \\
\hline+ & + & + & + & 18 \\
+ & + & - & + & 1 \\
+ & - & - & - & 4 \\
- & - & - & - & 95 \\
\hline
\end{tabular}

Culture was taken as the "gold standard" for $H$. pylori detection in biopsy specimens, in view of its high specificity and because it detected the largest number of patients among the routine diagnostic assays. The sensitivity, specificity, and positive and negative predictive values for the PCR were, respectively, 100, 96,83 and $100 \%$; for RUT they were 93,100 , 100 and $99 \%$; and for histology they were $100,100,100$ and $100 \%$.

Conclusion. The sensitivity of the PCR assay was similar to culture and the histological examination. The apparent lower specificity of the PCR assay may actually relate to the use of culture as the gold standard. The positive PCR results versus negative results in the other tests could reflect a non-eradicated infection of $H$. pylori or a cross-contamination in the laboratory or from the endoscopic apparatus.

\section{C:30 CITRIC ACID TEST MEAL ON ${ }^{13} \mathrm{C}$ UREA-BREATH TEST (UBT) FOR HELICOBACTER PYLORI (HP) IN ADULTS AND CHILDREN}

A. Alì, D. Vaira, V. Stanghellini, S. Salardi, M. Menegatti, N. Figura, F.A. Stella, F. Landi, C. Ricci, F. Mucci, V. Cuccaro, R. Corinaldesi, M. Miglioli, E. Cacciari. Dept of Int Med, Dept of Pediatrics, Bologna, Italia; Dept of Int Med, Siena, Cortex, Italia

Citric acid provides a higher and earlier peak in expired ${ }^{13} \mathrm{CO} 2$ compared to caloric test meals. Aim: to assess the reliability of UBT MAT (Cortex Italia) with and without an acidic test meal in adults and children. Subjects: In
8 consecutive endoscoped adults (M/F:4/4, age 22-54 yrs) with idiopathic dyspepsia (ID) biopsies (culture/urease/histology) \& IgG were performed. Patients were considered HP +ve if $3 / 4$ tests were +ve. In 12 children (M/F:6/6; 8-16 yrs) IgG and Western Blotting were perfomed for HP status determination (+ve if both tests +ve). $11 \mathrm{HP}$ - ve children (M/F:7/4; 7-15 yrs) were enrolled as controls. UBT: Each subject underwent UBT in two separate occasions, at least 5 days apart. A double base line breath sample $\left(\mathrm{TO}_{\mathrm{I}}, \mathrm{TO}_{\mathrm{II}}\right)$ was collected immediately after ingestion of half a 200 mls test water solution with or without $1.5 \mathrm{~g}$ of citric acid according to a randomized protocol. Subjects then ingested the remaining test solution plus $75 \mathrm{mg}$ of ${ }^{13} \mathrm{C}$-urea dissolved in $50 \mathrm{mls}$ of water. A 2nd double sample breath was collected after $30 \mathrm{~min}\left(\mathrm{~T} 3 \mathrm{O}_{1}, \mathrm{~T} 30_{\mathrm{III}}\right)$. The ${ }^{13} \mathrm{CO}_{2} /{ }^{12} \mathrm{CO}_{2}$ ratio in the T30 sample compared with a standard, $\times 1000$, minus base line value was calculated.

\begin{tabular}{llllll}
\hline${ }^{13} \mathrm{C}$ UBT & & $2+v e$ & $8-v e$ & $\begin{array}{l}12+v e \\
\text { children }\end{array}$ & $\begin{array}{l}11-\mathrm{ve} \\
\text { children }\end{array}$ \\
\hline delta/1000 citric acid: & $\mathrm{TO}_{\mathrm{I}} / \mathrm{T} 30_{\mathrm{I}}$ & 31.95 & 0.37 & 39.15 & 0.47 \\
& $\mathrm{TO}_{\mathrm{II}} / \mathrm{T} 30_{\mathrm{II}}$ & 31.88 & 0.35 & 39.88 & 0.39 \\
no citric acid: & $\mathrm{TO}_{\mathrm{I}} / \mathrm{T} 30_{\mathrm{I}}$ & 13.18 & 0.26 & 18.19 & 0.73 \\
& $\mathrm{TO}_{\mathrm{II}} / \mathrm{T} 30_{\mathrm{II}}$ & 12.98 & 0.44 & 18.48 & 0.52 \\
\hline
\end{tabular}

Conclusion: ${ }^{13} \mathrm{C}-\mathrm{UBT}$ with and without citric acid is effective and reproducible to identify HP status in adults and children.

\section{C:31 THE UPDATED SYDNEY SYSTEM (UPS): A FIELD TEST}

C. Ricci, N. Salfi, M. Menegatti, P. Bacchini, B. Massardi, F. Landi, A. Alì, F. Mucci, G. Martinelli, M. Miglioli, D. Vaira. Ist Medical Clinic \& Dept. of Histopathology, University of Bologna, Italy

Four years after the Sydney classification a group of pathologists from all over the world met in Houston to reappraise the UPS. Aim: To assess the usability of the UPS in the "real world". Methods: In a 3 months period, 113 endoscoped dyspeptics (M/F 55/58; range 19-87; mean 49.7 yrs) were enrolled. According to UPS, 5 biopsies were obtained: antrum $(A)=2$; corpus $(C)=2$; angulus $(\mathrm{AN})=1$. In addition 2 antral biopsies were taken for culture and urease test respectively. The specimens were histologically assessed and scored according to the UPS guidelines. 2/3 techniques testing positive gave HP status.

Results: 68/113 (60\%) were HP +ve (histology/urease test/culture). The endoscopic findings were: macroscopically normal $(n=26$; $\mathrm{HP}+50 \%)$, antral gastritis $(n=59, \mathrm{HP}+54 \%)$, erosive duodenitis $(n=12, \mathrm{HP}+67 \%)$, gastric ulcer $(n=5, \mathrm{HP}+80 \%)$ and duodenal ulcer $(n=11, \mathrm{HP}+100 \%)$. The sensitivity and specificity of the samples taken were: A 91 \& 87; C 89 \& 84; AN 89 \& 84; A + AN 98 \& 98; A + C 97 \& 95; AN + C 97 \& 95\% respectively. The gastric mucosa was histologically normal in 27 subjects. Of the HP infected patients 10 had antral predominant gastritis; 15 had diffuse non atrophic gastritis; 38 had multifocal atrophic gastritis (MAG), and none had corpus predominant gastritis. Antral predominant gastritis was present in 4/11 DU patients, while all the $5 \mathrm{GU}$ patients had MAG. The biopsies from the angulus revealed 15 cases of athrophy (moderate 1 and mild 14) that would otherwise not have been detected. Conclusions: UPS is easy to use. The additional biopsy specimen from the angulus added little to the diagnosis. However, in geographic areas with high prevalence of gastric carcinoma it may help detect early pre-neoplastic lesion.

\section{C:32 BREATH TEST FOR THE DIAGNOSIS OF H. PYLORI INFECTION: CONCORDANCE WITH HISTOLOGIC METHODS AND CORRELATION WITH HISTOLOGIC LESIONS OF GASTRIC MUCOSA}

J.P. Gisbert, D. Boixeda, C. Redondo, I. Alvarez Baleriola, I. Jiménez ', J.I. Pérez García ', J.M. Pajares '. "Ramón y Cajal" Hospital, Madrid, Spain; " "la Princesa" Hospital, Madrid, Spain

Purpose: To study the concordance between ${ }^{13} \mathrm{C}$-urea breath test and histology in the diagnosis of $H$. pylori infection, and to evaluate whether there is a correlation between breath test values and histologic lesions of gastric mucosa.

Methods: One-hundred and sixty-one patients with duodenal ulcer were prospectively studied. An endoscopy with biopsy samples (H\&E stain) taken from antrum and body was performed, and a ${ }^{13} \mathrm{C}$-urea breath test (according to the European standard protocol, measuring ${ }^{13} \mathrm{C}$ difference: $\left.\delta^{13} \mathrm{CO}_{2}\right)$ was also performed at initial moment. Both procedures were repeated one month after completing therapy: "classic" triple therapy, omeprazole or lansoprazole plus one antibiotic, or omeprazol plus two antibiotics (amoxycillin, clarithromycin, metronidazole). Eradication was defined as the absence of $H$. pylori both by histologic and breath test methods.

Results: At initial moment, $95.6 \%$ of patients $(\mathrm{n}=153)$ were $\mathrm{H}$. pylori positive by histologic methods, and $97.5 \%(\mathrm{n}=156)$ were positive by 
breath test (proportion of positive agreement $=0.98$ ). Kappa for $H$. pylori diagnosis after therapy was 0.88 (EE: 0.08 ). A correlation between $\delta^{13} \mathrm{CO}_{2}$ and histologic lesions at initial moment was observed, both at the antrum $(r=0.23 ; p<0.01)$ and body $(r=0.27 ; p<0.01)$. Similarly, a correlation after therapy in both gastric antrum $(0.55 ; \mathrm{p}<0.001)$ and body $(0.3 ; \mathrm{p}$ $<0.001$ ) was demonstrated. A significant difference was observed when comparing mean $\delta^{13} \mathrm{CO}_{2}$ in patients with different degrees of histologic gastritis, both at initial moment (antrum: W Kruskal-Wallis $=9 ; p=0.05$; body: $\mathrm{W}=12, \mathrm{p}<0.05$ ) and after therapy (antrum: $\mathrm{W}=60, \mathrm{p}<0.001$; body: $\mathrm{W}=23, \mathrm{p}<0.001$ ).

Conclusion: A high concordance was observed between ${ }^{13} \mathrm{C}$-urea breath test and histology in the diagnosis of $H$. pylori infection. A correlation exists between breath test values and histologic lesions of gastric mucosa.

\section{C:33 IS THERE ANY CORRELATION BETWEEN ${ }^{13} \mathrm{C}$-UREA BREATH TEST VALUES AND RESPONSE TO H. PYLORI ERADICATION THERAPY?}

J.P. Gisbert, D. Boixeda, C. Martín de Argila, F. Bermejo, T. Pérez, I. Jiménez ${ }^{1}$, J.M. Pajares ${ }^{1}$. "Ramón y Cajal" Hospital, Madrid, Spain;

1 "la Princesa" Hospital, Madrid, Spain

Purpose: To study whether there is a correlation between urea breath test values prior to treatment and the response to $H$. pylori eradication therapy in patients with duodenal ulcer.

Methods: Two-hundred and one patients with duodenal ulcer were retrospectively studied (mean age: $47 \pm 13$ years; $69 \%$ males). Initially, an endoscopy with biopsy samples (H\&E stain) taken from antrum and body and a ${ }^{13} \mathrm{C}$-urea breath test (according to the European standard protocol, measuring ${ }^{13} \mathrm{C}$ difference: $\delta^{13} \mathrm{CO}_{2}$ ) were performed. Both procedures were repeated one month after completing therapy: "classic" triple therapy $(n=$ 29 ), omeprazole or lansoprazole plus amoxycillin $(n=58)$, and omeprazol plus two of the following antibiotics: amoxycillin, clarithromycin, metronidazole $(n=114)$.

Results: Overall, eradication was achieved in $66 \%(\mathrm{n}=132)$. The corresponding rates for the therapy groups were: "classic" triple therapy: $64 \%$; omeprazole or lansoprazole plus amoxycillin: $33 \%$; omeprazol plus two antibiotics: $83 \%$. Mean $\delta^{13} \mathrm{CO}_{2}$ level was $31.5 \pm 23$. There were no differences when comparing values of patients with therapy success (33 $\pm 24)$ and failure $(30 \pm 20)$. No differences were observed when considering therapies separately and comparing eradication rates depending upon breath test levels prior to therapy. Breath test values did not influence the eradication in the logistic regression model. Mean $\delta^{13} \mathrm{CO}_{2}$ values after therapy in patients with eradication failure ran in parallel with initial values.

Conclusion: No correlation was observed between urea breath test values before treatment and the response to $H$. pylori eradication therapy in patients with duodenal ulcer. Thus, we conclude that quantitation of this diagnostic method is not useful to predict the success or failure of eradication therapy.

\section{C:34 CagA PROTEIN SEROPOSITIVITY IN RANDOM POPULATION AND IN GASTRIC CANCER PATIENTS}

T. Vorobjova ${ }^{1}$, I. Nilsson ${ }^{2}$, K. Kull ${ }^{1}$, H.-I. Maaroos ${ }^{1}$, A. Covacci ${ }^{3}$, T. Wadström ${ }^{2}$, R. Uibo ${ }^{1} .^{1}$ University of Tartu, Estonia, Sweden;

${ }^{2}$ University of Lund, Sweden; ${ }^{3}$ IRIS, Siena, Italy

Purpose. To evaluate the presence of antibodies to the H. pylori (HP) specific CagA protein, associated with the risk of development of gastric cancer (GC), in Estonian adult population with high prevalence (87\%) of HP infection, and compare it to the presence of antibodies to CagA in GC patients.

Subjects and methods. 199 subjects ( $87 \mathrm{M}, 112 \mathrm{~F}$, average 41 years) as representatives of a 1461 adult population from Southern Estonia, and 45 patients (22 M, $23 \mathrm{~F}$, average 67 years) with adenocarcionoma, operated at the Oncological Clinic in Tartu, were analysed. The antibody status was determined by serological evaluation of the IgG response to glycine extracted cell-surface proteins of HP-strain NCTC 11637 (HP-ELISA). Anti-CagA IgG was determined by ELISA using a recombinant fragment of the CagA protein (Covacci A, Siena) as solid phase antigen (1.24 $\mu \mathrm{g} / \mathrm{ml})$. The absorbence value 0.3 OD was taken as cut-off level based on results from $25 \mathrm{HP}$-negative sera (histology, serology).

Results. HP-ELISA: antibodies were revealed in 169/199 (85\%) in the population, and in $41 / 45(91 \%)$ of GC patients ( $p>0.05)$. CagA-ELISA: antibodies were found in 126/199 (63\%) of the population (6/30 among the HP-ELISA negativ persons). Among the 20-29 years old, a higher anti-CagA prevalence was found (76\%). In the GC patients the prevalence of anti-CagA was $87 \%$ (39/45).

Conclusions. Seropositivity in HP-ELISA was similarly high in Estonian adult population and GC patients. The prevalence of anti-CagA antibodies was significantly higher in the GC-patients than the population studied ( $p$
$=0.002)$. The persons in the group of 20-29 years, that showed the highest anti-CagA prevalence, indicate that further attention is needed in relation to gastric cancer development.

\section{C:35 IMMUNOBLOT FOR SERODIAGNOSIS OF HELICOBACTER} PYLORI

I. Nilsson, Å. Ljungh, P. Ahleljung, T. Wadström. Department of Medical Microbiology, University of Lund, Sweden

An immunoblot assay (IB) for analysis of specific IgG-antibodies to $H$. pylori (HP) cell surface proteins was evaluated. The IB was carried out by testing sera from patients with a positive and negative culture of gastric biopsies $(n=80)$. To monitor crossreactivity, a panel of sera from patients with other diseases than HP-infection were tested $(n=40)$, as well as sera from healthy blood donors $(n=100)$. Sera were initially analysed in EIA (enzyme immunoassay). Acid glycine extracted cell-surface proteins from HP-strain (CCUG 17874) served as antigen in both the EIA and the immunoblot.

In sera from culture positive patients a strong antibody reactivity to three major protein sections of low (26-33 kD), medium (43-66 kD), and high molecular masses $(85-120 \mathrm{kD}$ ) were found. In sera from patients with unrelated diseases and from HP-culture negative patient sera, antibody activity to the 43-66 kD-proteins was observed, indicating that some of these proteins (flagelin, HSP, urease) could be responsible for crossreactivity with antigens of other bacterial species.

The immunoblot was thus defined positive when sera stained the high as well as the low molecular proteins (reactivity to the medium sized proteins were ignored). The agreement between positive culture of biopsies and immunoblots was $98 \%$, compared to EIA (88\%). Results from this study show that immunoblot has high specificity in diagnosing HP-infections and uncertain results (border-line values) in EIA was possible to confirm by immunoblot.

\section{C:36 IMMUNOBLOT ANALYSIS OF SERA WITH DOUBTFUL RESULTS IN HELICOBACTER PYLORI IgG-EIA}

I. Nilsson, Å. Ljungh, B. Zeeberg, T. Wadström. Medical Microbiology, University of Lund, Sweden

The aim of the study was to investigate if it was possible, by using immunoblot (IB), to confirm or exclude an antibody response to specific antigens from Helicobacter pylori (HP) in serum samples giving uncertain results in HP-EIA (enzyme immuno assay). Sera from 218 patients with gastric pathology, giving borderline or low positive values in the HP-EIA were selected to be evaluated in IB. The HP-strain, CCUG 17874 was used for preparation of the acid glycine extracted cell-surface proteins, that served as antigens in the two assays. A sera was considered as positive in IB, when antibody activity to the high molecular proteins $(85-120 \mathrm{kD}$ ) and/or at least to two of the following proteins of low molecular size: 26 , $29,30-33 \mathrm{kD}$, was clearly visible.

Results. Out of 98 borderline sera, $40(41 \%)$ became IB negative and 58 $(59 \%)$ positive. Among the sera $(n=78)$ that showed EIA-values adjucent to the cut-off, $45(58 \%)$ became IB negative and $33(42 \%)$ positive. For 42 sera with low positive antibody levels in EIA, 4 (9.5\%) became IB negative and $38(90 \%)$ positive. Results from this study demonstrate that the immunoblot assay will be of great help in sorting out false positive results (crossreactive) or to confirm a HP-specific antibody response in sera with low antibody levels (false negative).

\section{C:37 HOW CERTAIN ARE YOU THAT YOU HAVE ERADICATED HELICOBACTER? A PROSPECTIVE STUDY}

\section{G. Daskalopoulos, Y.Y. Ho, D. Mehanna, K. Chen. Inner West Endoscopy,} Sydney, Australia

Introduction: What constitutes adequate assessment of $\mathrm{H}$. pylori eradication remains debatable. After antibiotic therapy if $\mathbf{H}$. pylori is not eradicated the distribution of the bacteria often becomes patchy with smaller numbers of bacteria present, making eradication confirmation with certainty difficult. Some studies have claimed high recurrence rates of $\mathrm{H}$. pylori after treatment quoting only histology as the method of determining eradication. Aim: To determine what constitutes an adequate assessment of Helicobacter eradication. Method: Patients returning for follow up endoscopy 4 weeks after triple therapy between January 1995 and July 1995 were prospectively assessed for $\mathrm{H}$. pylori eradication. Five biopsies were carried out in each patient and were independently and blindly assessed with: (1) Urease test, (1) phase contrast microscopy, (1) histopathology (giemsa) and (2) microbiological cultures. Patients in whom all four modalities were negative were considered to have been successfully treated and the Helicobacter eradicated. This group was removed from analysis. Patients who were 
found to have a positive result in any modality were considered to still have $H$. pylori present and were retained for analysis. In regards to the diagnostic methods, culture and histology were sent to a private laboratory and phase microscopy and urease testing (read as negative/positive after 24 hours) was done in-house. Statistical analysis was performed for non-parametric data using the Mann-Whitney rank sum test, and the Pearson product moment correlation. Results: 52 patients were found to have persistent $\mathrm{H}$. pylori infection after treatment. Of this group $(52 \%)$ were male and $(48 \%)$ female. The average age was 52 years. On analysis of the data 48 of $52(92.3 \%)$ patients were positive on urease testing, 48 of $52(92.3 \%)$ were positive on phase microscopy, 44 of $52(84.6 \%)$ were positive on histopathology and 28 of $52(53.9 \%)$ were positive on culture. There was no significant difference between urease, phase or histology in confirming the presence of $\mathrm{H}$. pylori after treatment. However, culture was significantly inferior to all the other three modalities. $(p<0.05)$. On histological examination alone $84.6 \%$ ( 44 patients) were confirmed positive. With the addition of phase microscopy a total of $94.2 \%$ (a further 5 patients) were confirmed positive. With the further addition of urease testing $96.2 \%$ (1 further patient) was confirmed positive. Using the two in office tests of phase contrast microscopy and urease testing $96.2 \%$ of all cases could be detected after treatment. Conclusions: 1 . Of the patients who were Helicobacter positive after treatment, $15 \%$ were not detected by histology. 2 . The in house tests of urease and phase microscopy will detect up to $96 \%$ of $\mathrm{H}$. pylori not eradicated by treatment. 3. A combination of test modalities provides the greatest detection of $\mathrm{H}$. pylori after treatment.

\section{C:38 CAN YOU DIAGNOSE HELICOBACTER PYLORI BY MACROSCOPIC APPEARANCES ON ENDOSCOPY?- (PHASE 1 TRIAL)}

Y.Y. Ho, G. Daskalopoulos. Inner West Endoscopy, Sydney, Australia

A recent study (1994) indicated that there was no correlation between the macroscopic appearance of the gastric mucosa and the presence of HP. We dispute this finding. We believe that there are certain subtle changes in the gastric mucosa which can be used to predict the presence of HP and the purpose of this study is to delineate this. The following parameters were used: antral erosions or erythematous gastritis, nodular gastritis, mosaic or cobblestone mucosa, erythematous speckles in the fundus (fundal speckling), fundal rugae hypertrophy, gastric body and/or fundal erythematous or erosive gastritis, intestinal metaplasia, gastric ulcer, gastric or pyloric deformity, duodenitis, duodenal ulcer, duodenal scarring or deformity. The presence of one or more of these parameters (observed by the endoscopist during the endoscopy) were then correlated to the presence or absence of HP as confirmed by phase contrast microscopy, histology and rapid urease test. Subjects who fulfilled a parameter but were negative on phase microscopy, histology and urease were checked with $\mathrm{Cl} 4$ breath test in addition. 202 consecutive patients who attended the GI clinic were used in this study. Excluded were those on NSAIDs or anticoagulants, known HP infestation, recent antibiotics, previous treatment for HP. Results: In 131 subjects - the presence of one or more parameters on endoscopy correlated with the presence of HP. There were 12 subjects in whom there were no parameters fulfilled, whom nonetheless had HP. In 2 subjects, there were 1 existing parameter each but there was no HP infestation and this was confirmed by a negative $\mathrm{C} 14$ breath test. 57 subjects were normal on endoscopy and were negative for HP. The presence of 1 or more of these parameters correlated to the presence of HP infestation with a sensitivity of $91.6 \%$ and specificity of $96.6 \%$. Conclusion: An overwhelming majority of the subjects with HP $(91.91 \%)$ had some gastric or duodenal mucosal changes albeit subtle. The macroscopic appearance of the gastric and duodenal mucosa are reliable indicators of the underlying presence of HP. Only $8.39 \%$ (12) of subjects with HP had no macroscopic changes in either the gastric of duodenal mucosa. There is a very low false positive $(0.93 \%)$. Phase 2 of this study will be to test the predictive value of these parameters in indicating HP infestation in a double blind setting.

\section{C:39 EVALUATION OF HELICOBACTER PYLORI SERODIAGNOSIS IN MONITORING TREATMENT SUCCESS}

T. Kubota, M. Tokieda, K. Murakami, T. Fujioka, M. Nasu. 2nd Department of Internal Medicine, Oita Medical University, Oita, Japan

Noninvasive methods, such as serological tests, have been employed as alternative procedures to determine the presence of Helicobacter pylori (H. pylori) infection. Serological tests for diagnosis are very helpful for epidemiological surveys. The purpose of this study was to monitor the antibody response after eradication of $H$. pylori.

Methods: To evaluate the usefulness of serology in monitoring treatment, we measured serial serum $H$. pylori IgG antibodies in eradication success and eradication failure patients. IgG antibody concentrations were measured by quantitative detection of ELISA kit (PILIKAPLATE G Heli- cobacter II) at before treatment, one month after treatment, six months and 1 year to monitor eradication.

Results:

\begin{tabular}{lllll}
\hline & Before & \multicolumn{3}{c}{ After treatment (months) } \\
\cline { 3 - 5 } & & 1 & 6 & 12 \\
\hline Eradication success $(\mathrm{n}=38)$ & 36.7 & 30.3 & $22.0^{*}$ & $18.9^{*}$ \\
Eradication failure $(\mathrm{n}=25)$ & 51.3 & 46.2 & 52.1 & 69.5 \\
\hline
\end{tabular}

${ }^{*} \mathrm{p}<0.05$

In the eradicated group, serum IgG concentrations decreased $17 \%$ by one month, $40 \%$ by six months and $49 \%$ by 12 months. The decrease was significant from six months after treatment. In the eradication failure group, serum IgG were no change. If a $15 \%$ reduction in IgG concentrations by six months was taken as an indicator for eradication of $H$. pylori, the sensitivity was $89.5 \%(34 / 38)$ and the specificity was $92 \%(23 / 25)$. Conclusion: We conclude that serology is a useful way to monitor $H$. pylori treatment success. Serologic tests are simple to perform and cause very little discomfort to patient.

\section{C:40 VALIDITY OF ${ }^{13}$ C-UREA BREATH TEST USING LASER SPECTROSCOPY FOR THE DIAGNOSIS OF HELICOBACTER PYLORI INFECTION}

M. Tokieda, T. Fujioka, T. Kubota, K. Murakami, M. Nasu ', Y. Higashi ${ }^{2}$. ${ }^{1}$ Second Dept. of Internal Medicine, Oita Medical University, Oita. Japan; ${ }^{2}$ Japan Radio Co., Tokyo, Japan

Background: The ${ }^{13} \mathrm{C}$-urea breath test $\left({ }^{13} \mathrm{C}\right.$-UBT $)$ is a useful non-invasive and accurate predictor from Helicobacter pylori $(H$. pylori). However, the device of mass spectroscopy (MS) is expensive and its operation complicated. In this study, the ${ }^{13} \mathrm{C}$-UBT using a new device of Laser Spectroscopy (LS), advantages of LS to MS, for diagnosing of $H$. pylori infection. Materials and Methods: One hundred twenty-five patients were evaluated for $H$. pylori infection by culture, histology and rapid urease test of endoscopic biopsy specimens. ${ }^{13} \mathrm{C}$-UBT was performed using both LS and MS. Fifty four patients were first examined cases, 55 and 26 were cases examined at 4 weeks and 6 months after $H$. pylori treated. For the ${ }^{13} \mathrm{C}$-UBT with LS, $100 \mathrm{mg}$ of ${ }^{13} \mathrm{C}$-urea was ingested. Breath samples were obtained before and 15 minutes after ${ }^{13} \mathrm{C}$-urea ingestion, and $\Delta{ }^{13} \mathrm{C}$ was measured by LS. A value of ${ }^{13} \mathrm{C}$-UBT with LS was considered positive when $\Delta{ }^{13} \mathrm{C}$ showed higher than $3 \%$. The results obtained with LS in $H$. pylori positive group were compared with those in negative one. Based on the results obtained both relationship, LS and MS, were then compared. Results: In the cases of first examination, ${ }^{13} \mathrm{C}$-UBT with LS resulted positive in 38 of 39 in $H$. pylori positive group and in all of 15 in $H$. pylori negative group. Eleven of 12 in $H$. pylori positive group and all of 43 in $H$. pylori negative group resulted positive at 4 weeks after, whereas the all of 2 in $H$. pylori positive group and all of 24 in $H$. pylori negative group at 6 months after treatment resulted positive. The sensitivity and specificity of ${ }^{13}$ C-UBT with LS (cut-off: $3 \%$ ) were $96.8 \%$ and $100 \%$ respectively. No significant difference was shown between results obtained with LS and MS $\left(y=-0.125+1.09 x, r^{2}=0.935\right)$. Conclusion: ${ }^{13} \mathrm{C}$-UBT with LS was as valid as ${ }^{13} \mathrm{C}$-UBT with MS for clinical diagnosis of $H$. pylori infection. However, since the former is much easier to use and less expensive, it may be an alternative to ${ }^{13} \mathrm{C}$-UBT with MS for the diagnosis of $H$. pylori infection.

\section{C:41 ASSESSMENT OF H. PYLORI STATUS: COMPARISON OF GIEMSA, DIFF-QUIK AND GENTA STAIN}

H.M.T. El-Zimaity, A.M. Segura, D.Y. Graham, R.M. Genta. V.A. Medical Center and Baylor College of Medicine, Houston, TX, USA

Background: The histopathologic detection of $H$. pylori in gastric biopsy specimens is considered the gold standard for the diagnosis of $H$. pylori infection. The Genta stain has a number of recognized advantages the most important being the ability to visualize the bacteria and the histological features of the gastritis or other gastric pathology on the same slide. Many pathologists use H\&E plus another stain for $\mathrm{Hp}$. Objective: To compare the sensitivity and specificity of Giemsa, Diff-Quik, and the Genta stain for detection of Hp. Methods: Cases were chosen to contain an approximately equal number of cases representing the full spectrum of $H p$ density (scale 0 to 5). One slide from each case was stained with each stain, coded, and examined independently by three pathologists. For each specimen, a visual analogue scale graded from 0 (absent/normal) to 5 (maximal intensity) was used to score $H$. pylori. In addition, the time passed evaluating the slides was tabulated. Disagreement between observers was resolved by consensus. Results: The sensitivity and specificity for the Giemsa, Diff-Quik, and Genta stain were $98 \%, 99 \%, 97 \%$, and $93 \%, 99 \%, 99 \%$, respectively. The time required to examine all 100 slides from each set was less with the Genta stain: 184, 225, and 85 min for Giemsa, Diff-Quik, and Genta 
stain, respectively. Conclusion: For those pathologists who prefer to use 2 stains for evaluation of gastric mucosal biopsies, the combination of H\&E and Diff-Quik appears to provide similar accuracy as the Genta stain but requires longer time.

\section{C:42 OPEN ACCESS ${ }^{13} \mathrm{C}$-UREA BREATH TESTS (OA $\left.{ }^{13} \mathrm{C}-U B T\right):$ COMPARISONS WITH AND IMPACT ON OPEN ACCESS ENDOSCOPY}

P. Moayyedi, M. Clough, E. Hemingborough, D.M. Chalmers, A.T.R. Axon. Centre for Digestive Diseases, General Infirmary at Leeds, $U K$

Introduction: We have recently introduced an $\mathrm{OA}^{13} \mathrm{C}-\mathrm{UBT}$ service to GPs. Patients $<40$ years with dyspepsia were eligible and were given a ${ }^{13} \mathrm{C}$-UBT at the LGI. $H$. pylori positive patients were given eradication therapy and a repeat ${ }^{13} \mathrm{C}$-UBT 2 months later. $H$. pylori negative patients were referred back to their GP. We wished to determine if this service reduced referral to open access endoscopy (OAE). Methods: Referral patterns to the $\mathrm{OA}^{13} \mathrm{C}$ UBT and OAE in patients $<40$ years were evaluated retrospectively and a validated dyspepsia questionnaire was administered to a proportion of patients attending each service. Results: 170 patients attended the $\mathrm{OA}^{13} \mathrm{C}$ UBT between Aug 95-Feb 96 . There was no difference in $H$. pylori status, age, gender or smoking between $\mathrm{OA}^{13} \mathrm{C}$-UBT and OAE patients. There were higher dyspepsia scores in the $\mathrm{OA}^{13} \mathrm{C}$-UBT patients compared with the OAE group $(16 \pm 8$ vs $11 \pm 6 \mathrm{p}<0.001)$ and more $\mathrm{OA}^{13} \mathrm{C}$-UBT patients were taking anti-secretory drugs $(52 \%$ vs $28 \% \mathrm{p}=0.03)$. In Aug 94-Feb $95236 / 714$ of all OAE were in patients $<40$ years. After the introduction of the $\mathrm{OA}^{13} \mathrm{C}$-UBT this has fallen to $183 / 712$ (30\% reduction $\mathrm{p}=0.03$ ). Only 5 patients referred for an $\mathrm{OA}^{13} \mathrm{C}$-UBT have subsequently been referred for endoscopy (all $H$. pylori negative). Conclusions: The $\mathrm{OA}^{13} \mathrm{C}$-UBT has reduced endoscopy referral in patients $<40$ years old.

\section{C:43 ESTABLISHMENT OF A SIMPLE AND RAPID ${ }^{13}$ C-UREA BREATH TEST}

M. Kato, M. Sukegawa, M. Katagiri, H. Kagaya, M. Kudo, K. Nishikawa, K. Hokari, H. Takeda, M. Aasaka. Hokkaido University, Sapporo, Japan

Aims: The ${ }^{13} \mathrm{C}$-urea breath test $\left({ }^{13} \mathrm{C}\right.$-UBT) is a non-invasive method for the diagnosis of $H$. pylori infection. The potential role of ${ }^{13} \mathrm{C}$-UBT in assessing cure of $H$. pylori infection should be considered. It is therefore important to develop, modify, and standardise ${ }^{13} \mathrm{C}$-UBT into a cheap, easy, reproducible method. The aim of the study is to determine the utility of a 10 minute ${ }^{13} \mathrm{C}$-UBT which is simple and short-term method. Methods: We investigated some factors affecting ${ }^{13} \mathrm{C}$-UBT in 35 healthy male volunteers whose $H$. pylori status was known. 165 patients in whom the identification of $H$. pylori was established by rapid urease test, culture, and histology underwent ${ }^{13} \mathrm{C}$-UBT before and/or after eradication treatment. H. pylori infection was defined as positive culture or both positive RUT and histology. Non-infection status was defined as all negative results of three methods. Informed consent was obtained from all of the patients. After an overnight fast, they ingested $100 \mathrm{mg}$ of ${ }^{13} \mathrm{C}$-urea, and washed out in the mouth with water. Breath samples were obtained before and 10 min after ingestion of ${ }^{13} \mathrm{C}$-urea. The ${ }^{13} \mathrm{C} /{ }^{12} \mathrm{C}$ ratio was measured by mass spectrometry. Results: Test meal, posture during test, and amount of ${ }^{13} \mathrm{C}$-urea solution did not significantly affect the value of ${ }^{13} \mathrm{C}$-UBT within 10 minutes after the ingestion of ${ }^{13} \mathrm{C}$-urea. However, the cleansing of the mouth is a very important factor that affects 10 minutes ${ }^{13} \mathrm{C}$-UBT results. In study of 124 patients who didn't receive eradication treatment, the calculated sensitivity and specificity was $100 \%$ by setting cut-off point at $3.5 \%$. This cut-off point gave a sensitivity of $90.0 \%$ and a specificity of $97.0 \%$ in the 121 patients who received eradication treatment of $H$. pylori. Conclusion: A 10-minute urea breath test was simple and rapid method, and further useful for the detection of $H$. pylori before and after eradication treatment.

\section{C:44 A NEW AND SENSITIVE STAINING METHOD FOR DETECTION OF H. PYLORI COCCOID FORM}

T. Sugiyama, H. Iwaki, M. Mori, A. Yachi. Sapporo Medical University School of Medicine, Sapporo 060, Japan

Purpose: The urea breath test (UBT) is the most reliable method, however this is expensive and not available worldwide. As the more widespread method, the histologic detection is universally used. Although many staining methods can be used, all have defects on the sensitivity, times, cost, and visible prominence. In this study, we have established a new, sensitive and easy method for detection of $\mathrm{H}$. pylori, especially identification of the coccoid form. Methods: Dewaxed paraffin embedded sections were dipped in $0.4 \% \mathrm{w} / \mathrm{v}$ carbol fucshin solution for 2 minutes and then washed in tap water. Working Malachite green $(0.68 \% \mathrm{w} / \mathrm{v}$ in water) was applied on the section for 2 minutes. They were cleared by xylene and mounted on Biolite and observed. The sensitivity was compared with Giemsa staining and Genta staining in mirror sections. Results: H. pylori was easily recognized as a deep magenta form against a light green back and the coccoid form were recognized with high contrast. Nine of 13 CLO negative specimens were positive with the new stain $(69 \%)$, which were all positive with UBT, however, 4 positive with Genta staining (31\%) and 5 positive with Giemsa staining (38\%). In 37 specimens after eradication therapy, coccoid forms were detected in 3 specimens with the new method, which were all negative with Giemsa stain and CLO test. Conclusion: We have established an easy, stable, convenient, low-cost and time saving method for $\mathrm{H}$. pylori detection in paraffin embedded tissue which was useful for identification of $\mathrm{H}$. pylori coccoid form.

\section{C:45 COMPARISON BETWEEN THREE COMMERCIALLY AVAILABLE SEROLOGICAL METHODS AND ONE IN HOUSE IgG ELISA FOR THE DETECTION OF HELICOBACTER PYLORI ANTIBODIES}

B. Sunnerstam ${ }^{1}$, T. Kjerstadius ', M. Bergström ${ }^{2}$, J. Ejderhamn ${ }^{2}$. ${ }_{1}^{1}$ Centralsjukhuset Karlstad, Sweden; ${ }^{2}$ Huddinge sjukhus, Sweden

Background: Since raised serum antibody titer against $\mathrm{H}$. pylori is present in $40 \%$ of an adult Scandinavian population, using a serological method with a low sensitivity or specificity will result in a great number of missed truly seropositive cases or an equally great number of unnecessary further investigations in truly seronegative ones.

Aims of the Study: To compare our in house ELISA for serum IgG antibodies against $\mathrm{H}$. pylori with three commercially available serological tests.

Design: Cross-sectional study of children without gastrointestinal symptoms.

Subjects: 168 consecutive children (age 0-20 years), visiting our daycare unit for minor surgery or investigation of unrelated disease.

Methods: Blood was drawn from all subject för analysis of $\mathrm{H}$. pylori IgG antibodies by an in house ELISA and by the Pyloriset, Premier/HM-CAP and Helico-G kits. Cases with discordant results in the four methods were further examined with 13-C urea breath test and immunoblotting as gold standards.

Results: The results of the four tests were discordant in 28/168 samples. 14 of these were evaluated by both gold standards and $12 / 14$ were negative by both, 1/14 positive by both and 1/14 uncertain. As compared with the gold standards there were no false results with the in house ELISA, less than $2 \%$ false results with the HM-CAP/Premier and Pyloriset but $5.4 \%$ false positives with the Helico-G.

Conclusions: The Helico-G is the most unvalid of the methods and should not be used för screening purposes. Our own ELISA agreed in $100 \%$ with the gold standards.

\section{C:46 ACCURACY OF PARALLEL VS. SERIAL SERUM IgG TESTING TO DOCUMENT ERADICATION OF H. PYLORI}

D.H. Balaban ${ }^{1}$, M. Sue ${ }^{1}$, C. Charles $^{2}$, R. Doobay ${ }^{2}$, H. Reid ${ }^{2}$,

E. Morris ${ }^{2}$, S. Cambridge ${ }^{2}$, N. Green ${ }^{2}$, J. Peacock ${ }^{3}$, D.A. Peura ${ }^{1}$.

'Division of Gastroenterology and Hepatology, University of Virginia,

Charlottesville, VA, USA ${ }^{2}$ University of Guyana, Turkeyen, Guyana, S.A.; ${ }^{3}$ Enteric Products Inc., USA

The diagnostic value of decreasing IgG antibody titers to confirm $H$. pylori (HP) eradication is limited by the necessity to perform the tests in parallel on stored sera. Aim: To compare the accuracy of parallel (P) and serial (S) serologic monitoring for confirmation of HP eradication. Methods: Patients presenting to a single outpatient clinic with dyspeptic symptoms were tested for HP with an IgG serum blot immunoassay and confirmatory C14 urea breath test (UBT). HP+ subjects were randomized to receive omeprazole $20 \mathrm{mg}$ bid, clarithromycin $500 \mathrm{mg}$ bid, and metronidazole 500 $\mathrm{mg}$ bid (MOC) or amoxicillin $1 \mathrm{gm}$ bid (AOC) for 10 days. HP IgG titers were measured by ELISA pre-therapy and 6 months post-therapy either serially (separate plates) or in parallel (same plate). UBT was repeated at 4 weeks and 6 months to document HP status. Results: $106 / 222(47.7 \%)$ subjects screened were HP+. 85/106 (80.1\%) subjects completed therapy and were followed for 6 months. 4-week eradication rates were similar in both treatment groups (MOC $88 \%$ vs. AOC $87 \%, p=N S$ ). The mean percent decrease in IgG titers at 6 mo. among eradicated subjects was $41.2 \%(P)$ vs. $39.2 \%(S)[p=0.30]$. Sensitivity and specificity of a $25 \%$ decline in IgG titer as confirmation of HP eradication is shown below:

\begin{tabular}{lccl}
\hline 25\% IgG Decrease & Parallel & Serial & p-value \\
\hline Sensitivity & 83.3 & 88.4 & 0.35 \\
Specificity & 100 & 100 & NS \\
\hline
\end{tabular}


Conclusion: Serial or parallel serum IgG testing offers equivalent diagnostic accuracy for detecting HP eradication following therapy. Serial HP IgG testing does not require serum storage and is a cost effective alternative for confirmation of bacterial eradication in areas where UBT is unavailable.

\section{C:47 PERFORMANCES OF NATIVE AND RECOMBINANT ANTIGENS FOR HELICOBACTER PYLORI SEROLOGY}

M. Widmer, J.D. de Korwin ${ }^{1}$, P. Aucher ${ }^{2}$, J.M. Thiberge ${ }^{3}$, A. Labigne ${ }^{3}$, J.L. Fauchère ${ }^{2}$. Sanofi diagnostic Pasteur, Paris, France; ${ }^{1}$ University Hospital of Nancy, Paris, France; ${ }^{2}$ University Hospital of Poitiers, Paris, France; ${ }^{3}$ Institut Pasteur, Paris, France

To date, there is no consensus as for the more performing antigenic preparation for Helicobacter pylori (Hp) serology. We compared the performances of 3 groups of antigens (Ag): (a) preparations of native superficial Ags obtained from the Hp strain N6, from its aflagellated isogenic mutant $\mathrm{N}_{6} f \mathrm{lb} \mathrm{A}^{-}$or from 6 clinical strains, (b) recombinant Ags consisting in either fusion-proteins (MS2-CagA, MBP-HspA) or the UreA + UreB apoenzyme and (c) 2 commercial kits (Cobas Core/Roche and Pylori Stat/BioWhittaker). These Ags were used in ELISAs with 92 sera from dyspeptic patients who underwent gastric endoscopies with biopsies which were processed for culture of $\mathrm{Hp}$ and for histology. The capability of each $\mathrm{Ag}$ to predict $\mathrm{Hp}$ infection was assessed using the ROC curves method ("receiving operating characteristics"). The sensitivity values ranged from 59 to $78 \%$ with the recombinant Ags and from 90 to $100 \%$ with the native Ags or the commercial kits. All the specificity values were over $90 \%$ except with UreA + UreB (42\%). The best sensitivity values were observed with $\mathrm{N} 6$ and $\mathrm{N} 6 \mathrm{flb} \mathrm{A}^{-}$. The best specificity values were observed with MBP-HspA (100\%) and AgFA (97\%). The more performant Ags were N6flbA-, AgFA and the Cobas-core kit. Among the $61 \mathrm{Hp}$ positive patients, there was no difference between the Ab titers of patients with (34) or without (27) a peptic ulcer wathever the Ag used. We concluded that among the tested Ags, the native Ags are more performant than the tested recombinant Ags to predict $\mathrm{Hp}$ infection. No Abs to these antigens has been able to predict an ulcer.

\section{C:48 IMPACT OF ACID SUPPRESSIVE TREATMENT ON TESTS TO DIAGNOSE H. PYLORI INFECTION}

F. Lerang ${ }^{1}$, J.B. Haug ${ }^{2}$, B. Moum ${ }^{1}$, A. Bjørneklett ${ }^{3}$, T. Berge ${ }^{2} .{ }^{1}$ Dept. Med., Østfold Central Hospital, Fredrikstad, Oslo, Norway; ${ }^{2}$ Dept. Microb., Østfold Central Hospital, Fredrikstad, Oslo, Norway; ${ }^{3}$ Dept. Med. Rikshospitalet, Oslo, Norway

Objectives: To determine the sensitivity (SN), specificity (SP), negative (NPV) and positive (PPV) predictive value of six tests for $\mathrm{H}$. pylori (Hp), and examine the impact of prior acid suppressive therapy (H2RA) on test results.

Methods: From January to December 1995350 dyspeptic patients (245 peptic ulcer disease, 74 NUD, 31 miscellaneous; mean age 58 yrs., 202 $\mathrm{M} / 148 \mathrm{~F}$ ) were tested for $\mathrm{Hp}$ infection by 14C UBT, serology (Orion Diagnostica Pyloriset New EIA-G), and presence of Hp in antral biopsy specimens by rapid urease test (RUT), culture, microscopy (acridine stain) and laboratory urease test (LUT). Hp infection was defined by a minimum of two of six positive tests. Usage of H2RA during the last 4 weeks prior to testing was reported.

Results:

\begin{tabular}{llclc}
\hline Test & SN $(\%)$ & SP $(\%)$ & NPV $(\%)$ & PPV $(\%)$ \\
\hline 14C & 95 & 95 & 91 & 97 \\
IgG & 98 & 91 & 96 & 95 \\
RUT & 85 & 99 & 79 & 99 \\
Cult & 94 & 100 & 90 & 100 \\
Micro & 81 & 98 & 75 & 99 \\
LUT & 80 & 100 & 74 & 100 \\
\hline
\end{tabular}

By stratification to H2RA usage SN of RUT and LUT was significantly reduced from $92-79 \%$ and $88-73 \%$. Acid suppression had no impact on the other tests.

Conclusion: Invasive urease-based tests are less sensitive in patients on H2RA therapy. Culture is the most accurate test, while UBT and serology are accurate non-invasive alternatives.

\section{C:49 RAPID SEROLOGICAL TESTS IN THE ASSESSMENT OF DYSPEPTIC PATIENTS}

N. Breslin, J. Lee, M. Buckley, C. O'Morain. Dept. of Gastroenterology, Meath/Adelaide Hospitals, Dublin, Ireland

Introduction: Retrospective and prospective studies in young dyspeptics have suggested that screening strategies based on non-invasive $\mathbf{H}$. Pylori testing can reduce endoscopy workload by $28-36 \%$. These strategies propose that only HP +ive individuals should undergo endoscopy. Such approaches may fail to diagnose idiopathic ulcers and reflux disease as well as pathology in patients whose test is falsely negative. Our study investigated the outcome if endoscopy was initially performed in HP -ive patients only.

Methods: 70 consecutive patients (less than $45 \mathrm{yrs)}$ undergoing investigation of "ulcer-like" dyspepsia had invasive and non-invasive ("Office" Elisa; sens. $88 \%$, Spec. $82 \%$ /ocally validated) determination of HP status. Individuals found to be HP +ive at endoscopy received 1 week eradication therapy and HP -ive individuals received treatment based on their diagnosis. Patients were followed up for six months. Results were analysed according to our hypothesis, whereby serologically positive patients would have received eradication without endoscopy and -ive patients would have undergone endoscopy.

Results: Based on serological tests there were $38 \mathrm{HP}$ +ive and $32 \mathrm{HP}$ -ive subjects. During follow-up symptoms failed to improve significantly in $10 / 38$ of the HP +ive patients.

There were also $3 / 38$ serologically false +ive patients whose symptoms are unlikely to have responded to eradication therapy. Thus in our hypothesis $34 \%(13 / 38)$ of the serologically positive patients would have subsequently required endoscopy. The overall reduction in workload would have been $35.7 \%(25 / 70)$. In the serologically HP -ive individuals endoscopy diagnosed $2 \mathrm{HP}+\mathrm{ive}$ (false -ive) duodenal ulcers, $1 \mathrm{HP}+\mathrm{ive}$ (false -ive) duodenitis and one case of Barrett's oesophagus. In the serologically positive group there were 8 duodenal ulcers, no gastric ulcers and no malignancies.

Conclusion: Our results suggest that performing endoscopy in HP -ive young dyspeptic patients following non-invasive screening reduces endoscopy workload and has the advantage of detecting significant pathology occurring in the setting of a true or falsely negative non-invasive test.

\section{C:50 PREDICTING RECRUDESCENCE OF HELICOBACTER PYLORI (HP) INFECTION}

D.K. Hyde ${ }^{1,2}$, M. Buckley ${ }^{2}$, C.T. Keane ${ }^{1}$, C.A. O'Moráin ${ }^{1,2}{ }^{1}$ St. James's Hospital, Trinity College Dublin, Ireland; ${ }^{2}$ Meath/Adelaide Hospitals, Trinity College Dublin, Ireland

The aims of this study were to assess the use of a PCR technique, to determine whether this method could detect HP infection in dyspeptic and post-treatment patients and to determine whether PCR could predict relapse.

Methods: PCR (HP specific primers to the 16S rRNA gene) was performed on DNA from paraffin embedded antral biopsy sections. Southern blot was used to confirm specificity of the PCR product. By convention, patients are classified as being HP positive if two or more diagnostic tests are positive and HP negative if all tests are negative. If one conventional test is positive, the result is equivocal. Patients who gave negative or equivocal conventional results, but who were positive by the PCR technique, were followed up using the ${ }^{13} \mathrm{C}$-urea breath test (UBT) or gastroscopy.

Results: 74 patients ( $38 \mathrm{M}, 36 \mathrm{~F}$, mean age; 41.5 yrs, range; $17-87 \mathrm{yrs}$ ) were under investigation for dyspepsia $(n=56)$ or post-treatment $(n=18)$. $23(31 \%)$ patients were HP+, 43 patients $(58 \%)$ were $\mathrm{HP}-$ and in 8 patients (11\%) the result was equivocal. Of the patients negative or equivocal by conventional techniques, 21 were positive by PCR. Ten dyspeptic patients were followed up (mean 16.9 months) and 3 had HP infection. In 5 post-treatment patients who were followed-up, all were subsequently HP negative. Overall, in both groups, PCR correctly predicted HP status in 2/4 patients (50\%) with an equivocal result. The sensitivity, specificity, PPV and NPV for PCR were $100 \%, 67 \%, 65 \%$ and $100 \%$, respectively.

Conclusions: An equivocal result indicates a high risk of subsequent HP infection. PCR is a sensitive technique, however, it is associated with false positive results and incorrectly predicted HP status in our dyspeptic and post-treatment populations.

\section{C:51 RELIABLE CULTURE OF H. PYLORI (HP) FROM THE RAPID UREASE TEST-ONE LESS BIOPSY}

D.K. Hyde ${ }^{1.2}$, M. Buckley ${ }^{2}$, C.T. Keane ', C.A. O' Morain ${ }^{2} .{ }^{~}$ St. James's Hospital, Trinity College Dublin, Ireland; ${ }^{2}$ Meath/Adelaide Hospitals, Trinity College Dublin, Ireland

European guidelines recommend that 6 biopsies are used for HP diagnosis (histology; antral and corpus $\times 2$, microbiology; antral $\times 1$ and rapid urease test; antral $\times 1$ ). Culture is $100 \%$ specific and is an essential requisite for the determination of antimicrobial resistance in patients who fail first-line therapy. The aim of this study was to assess the feasibility of culturing HP from biopsies that had been previously used for the rapid urease test.

Methods: At endoscopy, 1 antral biopsy was used for the rapid urease test (CLOtest ${ }^{\circledR}$, Delta West Ltd, Australia), 1 for culture and 3 for histology. 
When the CLOtest turned positive, the biopsy was removed and placed in transport medium. Both transport media (CLO and routine culture biopsy) were sent to the laboratory for culture. Biopsies were cultured on blood agar and plates were incubated at $37^{\circ} \mathrm{C}$ for 4-7 days. HP was identified by typical colony morphology and the urease test.

Results: 63 patients with dyspepsia or patients who had not received HP eradication therapy were enrolled. The CLOtest turned positive (mean; 48.4 minutes) in $19(30 \%)$ of these patients. In patients whose CLOtest and histology was positive, routine culture isolated HP in only 17/19 patients (89\%). This was possibly due to a delay in transportation from the endoscopy room to the laboratory. Culture of the biopsies from positive CLOtests isolated HP in 16/19 (84\%) patients. Overall, HP was cultured from 16 positive CLOtest biopsies from 17 patients whose routine culture was also positive (94\%).

Conclusion: HP was cultured from $94 \%$ biopsies from positive CLOtests when the routine culture was also positive. The CLOtest biopsy is therefore suitable for culture and this removes the need for an additional biopsy, thus reducing the endoscopists workload/cost.

\section{C:52 HOW DO TWO DIAGNOSTIC TESTS FOR H. PYLORI AT 1 MONTH COMPARE TO TWO ${ }^{13} \mathrm{C}$-UREA BREATH TESTS (UBT) IN ASSESSMENT OF ERADICATION?}

P.G. Johnson ${ }^{1}$, A.E. Duggan ${ }^{2}$, C. Olson ${ }^{3} .{ }^{1}$ BSIA Ltd., UK; ${ }^{2}$ Glaxo Wellcome R \& D, UK; ${ }^{3}$ Abbott Laboratories, Illinois, USA

Introduction: To evaluate the eradication of $H$. pylori it has been suggested that either 2 diagnostic techniques might be used 1 month (m) post-treatment, or that UBT alone might be performed at both 1 and $3 \mathrm{~m}$ post-treatment. Data from 7 multinational studies conducted to the standards of Good Clinical and Laboratory Practice are presented for a series of time points.

Methods: Patients who had an active DU and positive CLOtest ${ }^{\text {TI }}$ pretreatment, were evaluated post-treatment. $H$. pylori was assessed by UBT (excess $3.5{ }^{13} \mathrm{CO}_{2}$ per mil = positive) and at least 1 other test, [CLOtest, histology $(\mathrm{Hx})$, or culture $(\mathrm{Cx})$ ], before and $1,3,6$, or $12 \mathrm{~m}$ post-treatment, dependent on study. UBT, $\mathrm{Hx}$ and $\mathrm{Cx}$ (antral and corpus biopsies) were processed by central laboratories. $H$. pylori status assigned from the pooled result of UBT at 1 and either 3,6 or $12 \mathrm{~m}$ was compared with the pooled result of two diagnostic tests at $1 \mathrm{~m}$, and also the UBT alone at $1 \mathrm{~m}$, in the same subset of patients.

Results:

\begin{tabular}{llll}
\hline & UBT $(1 \mathrm{~m}+3 \mathrm{~m})$ & $(1 \mathrm{~m}+6 \mathrm{~m})$ & $(1 \mathrm{~m}+12 \mathrm{~m})$ \\
& $\% H p-\mathrm{ve}(\mathrm{n}=277)$ & $\% H p-\mathrm{ve}(\mathrm{n}=477)$ & $\% H p-\mathrm{ve}(\mathrm{n}=69)$ \\
\hline Pooled UBT & 59.9 & 50.3 & 49.3 \\
Two tests 1 m & 62.1 & 54.7 & 50.7 \\
UBT alone 1 m & 64.3 & 56.0 & 50.7 \\
\hline
\end{tabular}

Conclusions: 2 diagnostic tests at $1 \mathrm{~m}$ post-treatment or the pooled result from 2 consecutive breath tests provide satisfactory alternatives in the definitive assessment of $H$. pylori eradication. UBT alone at $1 \mathrm{~m}$ gives a slightly elevated estimate of eradication, but on balance compares favourably for clinical practice by not requiring endoscopy whilst giving a rapid answer.

\section{C:53 ${ }^{13}$ C-UREA BREATH TEST - A RELIABLE DIAGNOSTIC TECHNIQUE FOR ASSESSMENT OF ERADICATION}

P.G. Johnson ' , A.E. Duggan ${ }^{2}$, C. Olson ${ }^{3} .^{1}$ BSIA Ltd., Brentford, Middx, UK; ${ }^{2}$ Glaxo Wellcome Research and Development, UK; ${ }^{3}$ Abbott Laboratories, Illinois, USA

Introduction: The sensitivity of any diagnostic test for $H$. pylori is most rigorously tested post-treatment. Here post-treatment results are presented from 7 multinational studies conducted to standards of Good Clinical and Laboratory Practice.

Methods: 1029 patients, who had active DU and a positive CLOtest ${ }^{\text {Tu }}$ pre-treatment, were evaluated post-treatment in a total of 1815 visits. $H$. pylori was assessed by ${ }^{13} \mathrm{C}$-Urea Breath Test (UBT) and at least one other test, [CLOtest, histology $(\mathrm{Hx})$, or culture $(\mathrm{Cx})$ ], before and $1,3,6$, or 12 months post-treatment, dependent on study. UBT, $\mathrm{Hx}$ and $\mathrm{Cx}$ were processed by central laboratories. Antral and corpus biopsies were taken. The effect of a cut-off of $\geq 5$ compared to $\geq 3.5$ excess ${ }^{13} \mathrm{CO}_{2}$ per mil for the UBT is examined. H. pylori status was assigned from the combined

\begin{tabular}{lll}
\hline Test & Sensitivity & Specificity \\
\hline UBT (3.5) & $98.7 \%$ & $98.3 \%$ \\
UBT (5.0) & $96.9 \%$ & $99.1 \%$ \\
Histology (Giemsa) & $98.8 \%$ & $99.1 \%$ \\
Culture & $75.0 \%$ & $98.8 \%$ \\
CLOtest & $95.6 \%$ & $98.9 \%$ \\
\hline
\end{tabular}

results of at least two tests. Single positive tests or otherwise anomalous results were reviewed using data from previous and subsequent visits.

Results are presented in the table.

Conclusion: The UBT is a convenient, non-invasive test which yields similar sensitivity for assessment of eradication as histology or CLOtest alone (using multiple biopsies and sites). A cut-off of 3.5 is recommended for increased sensitivity but the test is robust even at 5.0 excess ${ }^{13} \mathrm{CO}_{2}$ per mil.

\section{C:54 EARLY NON-INVASIVE DETECTION OF THE "CURE" OF HELICOBACTER PYLORI INFECTION WITH DECREASED SERUM PEPSINOGEN I AND II}

H. Kagaya, M. Kato, M. Katagiri, M. Sukegawa, Y. Nakamura, M. Kudo, K. Nishikawa, K. Hokari, Y. Ohae, J. Yoshida, H. Takeda, M. Asaka. Hokkaido University, Sapporo, Japan

Objectives: The aim of this study was to investigate the serum pepsinogen I and II levels in patients with peptic ulcer before and after eradication therapy against $H$. pylori, to demonstrate serum pepsinogen I and II are non-invasive, useful markers to determinate cure of $H$. pylori infection.

Methods: Subjects were consisted of $55 \mathrm{H}$. pylori positive patients with endoscopically proven 34 gastric ulcer and 21 duodenal ulcer. Initial and eradication diagnosis for $H$. pylori infection were histological examination, rapid urease test, culture, and $13 \mathrm{C}$ urea breath test. Diagnosis was done similarly within three months after the cessation of treatment. Patients received the combination therapy (lansoprazole $30 \mathrm{mg}$ for 42 or 56 days + amoxycillin $1.5 \mathrm{~g}+$ metronidazole $0.75 \mathrm{~g}$ for 14 days) or new triple therapy (lansoprazole $60 \mathrm{mg}+$ amoxycillin $1.5 \mathrm{~g}+$ metronidazole 0.75 $\mathrm{g}$ for 7 days). Serum pepsinogen (PG) I and II were measured by usual radio-immuno assay. Serum samples were obtained from patients before treatment and at the time of determinant of eradication.

Results: In the 35 patients who were successfully cured, pepsinogen levels were significantly decreased (PG I from $79.3 \pm 36.3 \mathrm{ng} / \mathrm{ml}$ to $54.2 \pm$ $19.5 \mathrm{ng} / \mathrm{ml}, \mathrm{P}<0.0001 \mathrm{PG}$ II from $21.6 \pm 11.1 \mathrm{ng} / \mathrm{ml}$ to $8.7 \pm 3.4 \mathrm{ng} / \mathrm{ml}$, $P<0.0001$ ) and Pepsinogen I/II ratio were significantly increased (from $3.85 \pm 0.97$ to $6.40 \pm 1.63, P<0.0001$ ). In contrast, there were not clear changes in PG I, PG II, PG I/II ratio in patients who were not cured.

Conclusions: These findings suggest that PG II and I/I ratio are useful markers in clinical evaluation of cure of $H$. pylori.

\section{C:55 EVALUATION OF CagA AND NATIVE ANTIGEN IN RAPID TESTS FOR HELICOBACTER PYLORI}

S. Rose ', C. Johnson ' , A. Pronovost ${ }^{1}$, H. Kleanthous ${ }^{2}$, T. Tibbits ${ }^{2}$, R. Rombauer ${ }^{2}$, T. Monath ${ }^{2}$ ' $^{1}$ Quidel Corporation, San Diego, California 92121; ${ }^{2}$ OraVax, Inc., Cambridge, Massachusetts 02139

Purpose: The use of CagA (cytotoxin-associated gene product) in quantitative ELISA's have reportedly differentiated patients with gastric or duodenal ulcers (by endoscopy) infected with virulent strains of $H$. pylori from patients infected with $H$. pylori but without ulcers. In this study we examined the clinical effectiveness of purified native antigen versus recombinant CagA antigen when used in the Quidel QuickVue ${ }^{\circledast}$ One-Step H. Pylori Test, a visually read, lateral flow immunoassay format.

Methods: The performance of tests with CagA and native antigens were compared to biopsy (culture, histology, CLOtest) in 133 endoscopycharacterized patients. Patients were classed as $H$. pylori positive if culture or histology or CLOtest were positive and were classed as negative if all three biopsy tests were negative.

Results: Rapid test correlations to biopsy results are shown in the table below:

\begin{tabular}{lcll}
\hline Patient & & \multicolumn{2}{l}{ Culture/Histology/Urease Agreement } \\
\cline { 3 - 4 } Category & $(\mathrm{n}=)$ & vs. Native Antigen & vs. CagA \\
\hline Ulcer* & $(32)$ & $84.4 \%(67-95 \%) \dagger$ & $81.3 \%(64-93 \%)$ \\
Gastritis & $(58)$ & $75.9 \%(63-86 \%)$ & $67.2 \%(54-79 \%)$ \\
Asymptomatic & $(44)$ & $90.7 \%(78-97 \%)$ & $72.1 \%(56-85 \%)$ \\
Overall & $(133)$ & $82.7 \%(75-89 \%)$ & $72.2 \%(64-80 \%)$ \\
\hline
\end{tabular}

*Gastric and duodenal ulcers combined, $\dagger$ Values in parentheses are $95 \%$ confidence intervals.

Conclusions: Initial results for this patient population indicate that both native and CagA One-Step rapid tests exhibit statistically identical results in each patient category except asymptomatics. Recombinant CagA appears to be a useful adjunct to native antigen in the rapid format and might be useful to differentiate more virulent $H$. pylori strains and identify those at higher risk of developing peptic ulcer disease. 
of CagA in patients with duodenal ulcer but is not able to distinguish a particular pattern in patients with GML.

\section{C:61 HELICOBACTER PYLORI ANTIBODIES AGAINST Cag A AND Vac A IN PATIENTS WITH CHRONIC GASTRITIS DUODENAL AND GASTRIC ULCER}

M. Nilius, G. Illies, U. Platzer, U. Schmidt-Wittig, A. Hackelsberger, P. Malfertheiner. Dept. Gastroenterology, Hepatology and Infect Diseases Otto-von-Guericke-University Magdeburg, Germany

Background: Serological studies have shown that $\mathrm{Cag}$ A producing strains of H. pylori are associated with duodenal ulcer. Antibody titers against $\mathrm{Cag}$ A correlate with severity of disease. Vac A always is coexpressed with Cag A.

Aim of the study was to investigate the antibody reaction against Cag A and Vac A of patients with chronic gastritis (CG) and gastric (GU) and duodenal ulcer (DU).

Methods: 133 patients undergoing upper gastrointestinal endoscopy were included. $H$. pylori infection was determined by urease test (HUT), histology and IgG-ELISA (Bio Whittaker). Patients were considered $H P$-positive if they were positive in 2 of these reference methods. Antibody response to specific $H$. pylori antigens was tested by a commercially available Immunoblot-System (BAG-Pylori-Blot).

Results: 116 from 133 patients had a positive Immunoblot (DU: 21/28 (75\%); GU: 23/32 (71.9\%); CG: 72/73 (98.6\%). Antibody reactions against the different antigens are summarized in the following table:

\begin{tabular}{llll}
\hline Antigen & DU & GU & CG \\
\hline $116 \mathrm{kD}$ (Cag A) & $23 / 28(82.1 \%)$ & $24 / 32(75 \%)$ & $53 / 72(73.6 \%)$ \\
$89 \mathrm{kD}$ (Vac A) & $11 / 28(39.2 \%)$ & $12 / 32(37.5 \%)$ & $38 / 72(52.8 \%)$ \\
$30 \mathrm{kD}$ (Ure A) & $17 / 28(60.7 \%)$ & $17 / 32(53.1 \%)$ & $45 / 72(62.5 \%)$ \\
$26.5 \mathrm{kD}$ & $24 / 28(85.7 \%)$ & $17 / 32(53.1 \%)$ & $56 / 72(77.8 \%)$ \\
$19.5 \mathrm{kD}$ & $13 / 28(46.4 \%)$ & $15 / 32(46.9 \%)$ & $33 / 72(35.8 \%)$ \\
\hline
\end{tabular}

Conclusion:

Whereas the serological profile to CagA and all other antigens was not significantly different between DU, GU and CG patients, serological profile to VacA was significantly associated with $C G$.

\section{C:62 EARLY NON-INVASIVE DETECTION OF THE "CURE" OF HELICOBACTER PYLORI INFECTION WITH DECREASED SERUM PEPSINOGEN I AND \|}

H. Kagaya, M. Kato, M. Katagiri, M. Sukegawa, Y. Nakamura, M. Kudo, K. Nishikawa, K. Hokari, Y. Ohae, J. Yoshida, H. Takeda, M. Asaka. Hokkaido University, Sapporo, Japan

Objectives: The aim of this study was to investigate the serum pepsinogen I and II levels in patients with peptic ulcer before and after eradication therapy against $H$. pylori, to demonstrate serum pepsinogen I and II are non-invasive, useful markers to determinate cure of $H$. pylori infection.

Methods: Subjects were consisted of $55 \mathrm{H}$. pylori positive patients with endoscopically proven 34 gastric ulcer and 21 duodenal ulcer. Initial and eradication diagnosis for $H$. pylori infection were histological examination, rapid urease test, culture, and $13 \mathrm{C}$ urea breath test. Diagnosis was done similarly within three months after the cessation of treatment. Patients received the combination therapy (lansoprazole $30 \mathrm{mg}$ for 42 or 56 days + amoxycillin $1.5 \mathrm{~g}+$ metronidazole $0.75 \mathrm{~g}$ for 14 days) or new triple therapy (lansoprazole $60 \mathrm{mg}+$ amoxycillin $1.5 \mathrm{~g}+$ metronidazole 0.75 $\mathrm{g}$ for 7 days). Serum pepsinogen (PG) I and II were measured by usual radio-immuno assay. Serum samples were obtained from patients before treatment and at the time of determinant of eradication.

Results: In the 35 patients who were successfully cured, pepsinogen levels were significantly decreased (PG I from $79.3 \pm 36.3 \mathrm{ng} / \mathrm{ml}$ to $54.2 \pm$ $19.5 \mathrm{ng} / \mathrm{ml}, \mathrm{P}<0.0001$ PG II from $21.6 \pm 11.1 \mathrm{ng} / \mathrm{ml}$ to $8.7 \pm 3.4 \mathrm{ng} / \mathrm{ml}$, $P<0.0001$ ) and Pepsinogen I/II ratio were significantly increased (from $3.85 \pm 0.97$ to $6.40 \pm 1.63, \mathrm{P}<0.0001)$. In contrast, there were not clear changes in PG I, PG II, PG I/II ratio in patients who were not cured.

Conclusions: These findings suggest that PG II and I/II ratio are useful markers in clinical evaluation of cure of $H$. pylori.

\section{C:63 HELICOBACTER PYLORI (HP) ANTIBODIES AGAINST Cag A PROTEIN IN BLEEDING AND NON-BLEEDING GASTRIC AND DUODENAL ULCERS}

G. Illies, M. Nilius, J.E. Dominguez-Munoz, A. Hackelsberger, B. Pepperkok ${ }^{1}$, P. Malfertheiner. Dept. Gastroenterology, Hepatology and Infect Diseases Otto-von-Guericke-University Magdeburg, Germany; ${ }^{1}$ Medical Laboratory Dr. Limbach, Heidelberg, Germany

Background: Cag A is a recognized indicator for increased $H$. pylor virulence and is more frequently detected in strains from patients with ulcer disease and gastric malignancy. The prevalence of CagA producing H. pylori strains in bleeding ulcers ins unknown. Aim of the study was therefore to evaluate the frequency of Cag A-antibodies in patients with bleeding and non-bleeding ulcers and chronic gastritis.

Methods: 100 patients, 30 patients with non-bleeding, 30 patients with bleeding gastric (GU) and duodenal ulcer (DU) and 40 patients with active chronic gastritis (CG) were included. All patients were examined of HP-infection by urease-test (HUT), histology, ${ }^{13} \mathrm{C}$-UBT and serology HP-serology was performed by a commercially available ELISA (BioWhittaker). Cag A determination was investigated by an ELISA, coated with recombinant Cag A protein (viva diagnostika) and by a commercial Western Blot (BAG-pylori-Blot).

Results: $87 / 100$ (87\%) were HP-positive by at least 3 tests. HP-antibodies were detected in $81 / 100(81 \%)$ of the patients, $61 / 100(61 \%)$ had also CagA antibodies in the CagA-ELISA. 80/100 (80\%) had a positive Western-Blot result. The profile of $\mathrm{CagA}$ and $\mathrm{VacA}$ antibodies within the three different patient groups is summarized in the following table:

\begin{tabular}{llll}
\hline & BU & NBU & CG \\
\hline Western-Blot & & & \\
Cag A & $22 / 30(73.3 \%)$ & $23 / 30(76.7 \%)$ & $27 / 40(67.5 \%)$ \\
Vac A & $11 / 30(36.7 \%)$ & $11 / 30(36.7 \%)$ & $19 / 40(47.5 \%)$ \\
CagA - ELISA & $22 / 30(73.3 \%)$ & $20 / 30(66.7 \%)$ & $19 / 40(47.5 \%)$ \\
\hline
\end{tabular}

Conclusion: CagA-antibodies are detectable in about $2 / 3$ of patients and are present as frequently in bleeding and non-bleeding ulcers and chronic gastritis. Antibodies against VacA seem to be higher in CG. However CagA as well as VacA are not useful indicators for predicting ulcer complications.

\section{C:64 ATTEMPTS TO CHARACTERIZE PCR INHIBITORS PRESENT} IN FAECES - APPLICATION TO HELICOBACTER PYLORI

L. Monteiro ${ }^{1}$, A. Vekris ${ }^{2}$, J. Bonnet ${ }^{3}$, D. Bonnemaison ${ }^{3}$, R. Vidal ${ }^{4}$,

F. Mégraud ${ }^{1}$. ' Laboratoire de Bactériologie, ${ }^{2}$ Laboratoire de Biochimie, ${ }^{3}$ Laboratoire d'Immunologie, Université de Bordeaux 2, Bordeaux, France; ${ }^{4}$ Laboratório de Engenharia Genética, Faculdade de Farmácia, Lisboa, Portugal

PCR in faeces is potentially an attractive non invasive method to detect $H$. pylori DNA in faeces but inhibitors of Taq polymerase constitute the main limitation in these highly complex specimens. Our goal was to get insight to the nature of inhibitors present in faeces. We used as target DNA, $H$. pylori DNA and/or a DNA built to be an internal control in a PCR detecting $H$. pylori. This target DNA is amplified using the same primers as $H$. pylor DNA (as described by Hammar et al.) and generates a 602 bp PCR product. Specimens were obtained on different days from 12 volunteers known to be $H$. pylori negative and spiked with a constant amount of appropriate DNA. DNA extraction was performed with the QIAamp tissue modified method. Potential inhibitors were then separated from a large amount of extracts using an Ultrogel AcA44 (molecular weight between 10,000 and 130,000). Characterization of inhibitors was performed successively by heating, lipid extraction, treatment with DNAase and glycosidases. Our results show that the QIAamp tissue method is able to remove most but not all of the PCR inhibitors.

Results of PCR obtained when specimens of faeces from different persons (1-12) at different times $(\mathrm{a}-\mathrm{c})$ were spiked with a constant amount of target DNA are as follows:

\begin{tabular}{|c|c|c|c|c|c|c|c|c|c|c|c|c|c|c|}
\hline \multirow[t]{2}{*}{ D } & \multicolumn{3}{|l|}{1} & \multicolumn{3}{|l|}{2} & \multirow[t]{2}{*}{3} & \multirow[t]{2}{*}{4} & \multirow[t]{2}{*}{5} & \multirow[t]{2}{*}{6} & \multirow[t]{2}{*}{7} & \multirow[t]{2}{*}{8} & \multirow[t]{2}{*}{$\begin{array}{ll}9 & 10\end{array}$} & \multirow[t]{2}{*}{$11 \quad 12$} \\
\hline & a & b & c & a & b & c & & & & & & & & \\
\hline $\begin{array}{l}1 / 1 \\
1 / 2 \\
1 / 10\end{array}$ & $\overline{+}$ & $\overline{+}$ & + & $\overline{-}$ & $\begin{array}{l}- \\
+1- \\
+\end{array}$ & $\begin{array}{l}- \\
+1- \\
+\end{array}$ & $\overline{+}$ & $\overline{+}$ & $\begin{array}{l}- \\
+1- \\
+\end{array}$ & + & $\begin{array}{l}- \\
+1- \\
+\end{array}$ & + & $\overline{+}$ & \\
\hline
\end{tabular}

D: dilution of the specimen

As can be seen in the table, the inhibitors vary in quantity from patient to patient and from one day to the other for a given patient. Characterization attempts show that they are not proteins, lipids, or DNA but could be acidic polysaccharides. This method is currently being used to detect $H$. pylori in faeces.

\section{C:65 DETECTION OF ANTIBODIES TO H. PYLORI CAgA PROTEIN BY FLOW CYTOMETRIC IMMUNOASSAY}

L.M. Best, S.J.O. Veldhuyzen van Zanten. Queen Elizabeth II Health Sciences Center, VGH, Halifax, Nova Scotia, Canada

Positive $H$. pylori whole cell serological tests do not identify the persons who have, or will progress to, gastric and duodenal ulcers and gastric carcinoma. CagA has been shown to be highly associated with ulcer disease. We determined the CagA antibody response in 72 patients using the Flow Microsphere Immunofluorescent Assay (FMIA) and Western Blots (WB). The CagA fusion protein ORV220 (OraVax, Cambridge, MA) was 
coated onto carboxylated magnetic microspheres appropriately blocked and washed. For each test $150 \mu \mathrm{l}$ of microspheres at $1 \times 10^{8} / \mathrm{ml}$ were added to $5 \mu \mathrm{l}$ of serum, incubated, washed, and reacted with FITC labelled anti-human IgG. A flow cytometer was used to collect and analyze the data. The serum samples were blotted and observed for the presence of antibodies to the approximately $128 \mathrm{kDa}$ CagA protein. Thirty-two of 39 $(82 \%)$ culture and histology positive patients were CagA positive by FMIA and $8(18 \%)$ were negative. Of the 33 negative sera $100 \%$ were negative. In every instance the WB result mirrored the FMIA result. Eleven patients undergoing triple therapy had decreasing CagA antibody levels at 6 and 36 weeks. FMIA provides a means for rapidly detecting and following the course of CagA antibody response.

\section{C:66 OPTIMAL MEDIA COMBINATION FOR SUCCESSFUL ISOLATION OF HELICOBACTER PYLORI FROM ANTRAL BIOPSIES}

R. Piccolomini, G. Di Bonaventura, S. Lupo, C. Della Pelle, M. Neri. “ $G$. D'Annunzio" University, Chieti, Italy

Culture analysis of $H$. pylori still has an important place in research as well as in routine investigation, especially when antibiotic susceptibility tests are required. A large number of different agar media for the successful culture of $H$. pylori have been proposed, but none of these by itself achieves an $100 \%$ recovery. Aim of our study was to compare eight media, 4 non selective and 4 selective, to determine the best media-combination for the primary isolation of $H$. pylori. Methods: over a period of 5 months, mucosal antral biopsies were obtained from 222 consecutive dyspeptic patients undergoing endoscopy. Biopsy samples were plated in parallel on all eight media: Egg Yolk Emulsion agar (EYE), Skirrow's medium, Dent's medium and modified Thayer-Martin medium were used as selective media; Chocolate agar (CHOC) with 5\% sheep blood, Triptycase Soy agar (TSA) with 5\% sheep blood, Brucella agar with 7\% horse blood laked and Brain-Heart Infusion agar with 7\% horse blood were used as nonselective media. Results: using these eight media, $\mathrm{H}$. pylori was recovered from $112 / 222$ patients, yielding an isolation rate of $50.5 \%$. Comparison of all possible combinations of the eight media showed that the highest rate of isolations of $\mathrm{H}$. pylori was $100 \%$ (112/112) with EYE + CHOC, followed by $96.4 \%(108 / 112)$ with EYE + TSA. Conversely, we found that none of media used alone yielded a rate of $100 \%$ (maximum recovery was 94.4\% provided by EYE agar). Conclusions: the association of the Egg Yolk Emulsion agar and Chocolate agar yielded maximum recovery of $H$. pylori from gastric biopsies. Therefore, the use of one selective and one non-selective medium in parallel offers optimal recovery rates with only a slight increase in costs.

\section{C:67 SERODIAGNOSIS OF H. PYIOII (HP) INFECTION BY A SECOND GENERATION ELISA TEST: COMPARISON BETWEEN ADULTS AND CHILDREN}

G.A. Rocha, D.M.M. Queiroz, A.M.R. Oliveira, E.N. Mendes, S.B. Moura, A.S.T. Carvalho, C.A. Oliveira. Lab. Res. Bacteriology/UFMG, Belo Horizonte, Brazil

According to some investigators, although ELISA tests are highly sensitive and specific for HP infection diagnosis in adults, the cutoff values to identify infection should be stated and the assay validated for pediatric population. This study was undertaken to evaluate IgG response to HP in children by a 2nd generation ELISA test and to compare the results with those obtained in adults. We studied 162 non-consecutive patients: 68 children ( 24 boys, mean age $9.6 \mathrm{yr}$, range 2 to $17 \mathrm{yr}$ ) and 97 adults ( 44 men, mean age $42.6 \mathrm{yr}$, range 20 to $78 \mathrm{yr}$ ) who underwent endoscopy for evaluation of symptoms referable to the upper gastrointestinal tract. The presence of HP was determined in antral biopsy specimens by culture, preformed urease test and carbolfuchsin stained smears. Serological evaluation for IgG antibodies to HP was assessed using Cobas-Core antiHP EIA (Roche, Switzerland) performed according to the instructions of manufacturer. Patients were considered HP positive when they presented at least 2 positive tests and negative when the 3 tests were negative. By this criterion 37 children ( 14 with duodenal ulcer) and 65 adults ( 31 with peptic ulcer) were HP-positive and 31 children and 32 adults were HP-negative. By using the cutoff stated by the manufacturer, antibodies to HP were detected in 62 of $65 \mathrm{HP}$-positive adults and in none of the negative ones. The sensitivity, specificity, positive and negative predictive values for the test for adults were $95.4 \%, 100 \%, 100 \%$ and $91.4 \%$ respectively. When the value of the cutoff recommended by the manufacturer was adopted, IgG antibodies to HP were detected in 30 of 37 infected children and in none of the noninfected ones. In children, the sensitivity, specificity, positive and negative predictive values were $81 \%, 100 \%, 100 \%$ and $81.5 \%$ respectively When the value of the cutoff was determined by using the mean of OD plus $3 \mathrm{SD}$, the sensitivity and specificity of Cobas-Core were $89.2 \%$ and $96.7 \%$, respectively. HP-negative children presented OD values significantly lower than the HP-negative adults $(p=0.0009)$.

\section{C:68 FLEXSURE ${ }^{\oplus}$ HRA WHOLE BLOOD TEST FOR IgG ANTIBODIES TO H. PYLORI}

W. Schrier, C. Jaseph, L. Stephens, T. Shepard, C. Crane, R. Schoengold. SmithKline Diagnostics (SKD), Inc., San Jose, CA, USA

Purpose: To describe the performance of a fingerstick whole blood test for IgG antibodies to $H$. pylori (FlexSure ${ }^{\circledast} H P$, SKD). Methods: Conjugate is rehydrated with two drops of Buffer. Blood $(\approx 70 \mathrm{uL})$ from a fingerstick is collected in a FlexSure ${ }^{\circledR}$ Capillary Tube coated with EDTA and a blood cell cross-linking reagent. When the sample is applied to the Test Strip, cross-linked blood cells are retained in the Sample Pad while plasma migrates up the Test Strip to an antibody capture zone containing $H$. pylori antigen (HM-CAP). The test device is closed when the sample reaches the Limit Line, the conjugate flows down the Test Strip, and test results are interpreted 4 min. after closure. Results: The FlexSure ${ }^{\circledast} H P$ whole blood and FlexSure ${ }^{\circledast}$ HP serum tests immunochemical characteristics are the same. Test performance was not affected by the addition of EDTA and the cross-linking reagent to serum, or the spiking of whole blood with high levels of cholesterol $(420 \mathrm{mg} / \mathrm{dL})$, triglycerides $(708 \mathrm{mg} / \mathrm{dL})$ and hemoglobin $(1650 \mathrm{mg} / \mathrm{dL})$. Within- and between-site reproducibility of FlexSure ${ }^{\circledast P}$ test were $99 \%$ vs. expected results. At least two gastric biopsies and matched whole blood and serum samples were obtained from 173 symptomatic g.i. clinic patients (mean age: $46 \mathrm{y}$.) for histology, rapid urease, FlexSure ${ }^{\circledast} H P$ serum, FlexSure ${ }^{\otimes} H P$ whole blood, and HM-CAP EIA testing. Overall agreement for FlexSure ${ }^{\circledast} H P$ whole blood vs. FlexSure ${ }^{\oplus} H P$ serum was $92 \%$. Overall agreement was $95 \%$ following resolution of discordant samples with biopsy. Sensitivity of FlexSure ${ }^{\circledR} H P$ whole blood and serum tests vs. biopsy were $88 \%$ and $92 \%$, respectively; specificity 74 and $76 \%$, comparable to other immunochemical tests. A separate group of 233 healthy volunteers (mean age: $23 \mathrm{y}$.) were tested with both FlexSure ${ }^{\circledast}$ HP methods and a relative specificity of $99 \%$ for whole blood vs. serum was obtained.

Conclusions: FlexSure ${ }^{\circledast}$ HP whole blood test is a simple, rapid, pointof-care test requiring $\approx 70 \mathrm{uL}$ of whole blood from a finger puncture. The test is well-suited for the physician's office and yields test results in 6 to 7 min. comparable to other serological tests for $H$. pylori antibodies.

\section{C:69 COMPARISON OF THREE WHOLE BLOOD RAPID TESTS FOR ANTIBODIES TO H. PYLORI}

C. Crane ${ }^{1}$, M. Hay-Kaufman ', T. Forrest ${ }^{2}$, S. Van Kell ${ }^{2}$. SmithKline Diagnostics (SKD), Inc., San Jose, CA, USA; ${ }^{2}$ Abbott Laboratories, Abbott Park, IL, USA

Purpose: Three rapid whole blood tests for antibodies to $H$. pylori; FlexSure ${ }^{\oplus}$ HP/FlexPack ${ }^{\mathrm{Tw}} \mathrm{HP}$ (SKD/Abbott), Helisal (Cortecs), and QuickVue One-Step (Quidel), were compared to HM-CAP EIA. Methods: Fingerstick whole blood samples from 219 healthy volunteers were run on the three rapid tests in accordance with the manufacturer's instructions using capillary tubes provided. Venous blood was also taken for serum EIA testing. Five EIA-indeterminate samples were removed from the database. Testing was blinded and results for each rapid test were independently compared to EIA to determine relative sensitivity, specificity and overal agreement. Results: Positivity rates were $33 \%$ for EIA, 38\% for FlexSure HP/FlexPack ${ }^{\mathrm{TW}} \mathrm{HP}, 63 \%$ for Helisal, and $34 \%$ for QuickVue.

\begin{tabular}{|c|c|c|c|}
\hline $\begin{array}{l}\text { Whole Blood } \\
\text { rapid test }\end{array}$ & $\begin{array}{l}\text { Relative } \\
\text { sensitivity }\end{array}$ & $\begin{array}{l}\text { Relative } \\
\text { specificity }\end{array}$ & $\begin{array}{l}\text { Overall } \\
\text { agreement }\end{array}$ \\
\hline $\begin{array}{l}\text { FlexSure }^{\circledast} H P / \text { FlexPack }^{\text {Tu }} \text { HP } \\
\text { Helisal } \\
\text { QuickVue }\end{array}$ & $\begin{array}{l}94.8 \% \\
96.1 \% \\
85.7 \% *\end{array}$ & $\begin{array}{l}90.8 \% \\
54.9 \% * \\
93.0 \%\end{array}$ & $\begin{array}{l}92.2 \% \\
69.4 \% * \\
90.4 \%\end{array}$ \\
\hline
\end{tabular}

*significant at $\mathrm{p}<0.01$ (relative to the other two rapid tests)

FlexSure ${ }^{\circledast}$ HP/FlexPack ${ }^{\text {tw }}$ HP required one capillary tube of blood $(\approx$ $70 \mathrm{uL}$ ), 3 steps, and 6 to $7 \mathrm{~min}$. of operator time to run. Helisal required one capillary tube $(\approx 30 \mathrm{uL}), 5 \mathrm{steps}$, and $15 \mathrm{~min}$. QuickVue required two capillary tubes $(\approx 100 \mathrm{uL})$, one step, and $10 \mathrm{~min}$. Conclusions: Helisal required the least blood volume but the $54.9 \%$ relative specificity limited the value of a positive result. QuickVue required the fewest steps, but had the lowest relative sensitivity $(85.7 \%)$ and required the largest blood volume. FlexSure ${ }^{\circledast}$ HP/Flexpack ${ }^{\text {Th }}$ HP had high relative sensitivity $(94.8 \%)$ and specificity $(90.8 \%)$, the highest overall agreement $(92.2 \%)$, and the shortest run time. 